\title{
IIIII
}

CROATIAN NATIONAL BANK

Working Papers W-47

\section{Are Sovereign Credit Ratings Overrated?}

Davor Kunovac and Rafael Ravnik 



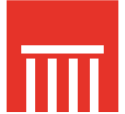

HNB

WORKING PAPERS W-47 


\section{PUBLISHER}

Croatian National Bank

Publishing Department

Trg hrvatskih velikana 3, 10002 Zagreb

Phone: +38514564555

Contact phone: +38514565006

Fax: +38514564687

\section{WEBSITE}

www.hnb.hr

EDITOR-IN-CHIEF

Ljubinko Jankov

\section{EDITORIAL BOARD}

Vedran Šošić

Gordi Sušić

Davor Kunovac

Tomislav Ridzak

Evan Kraft

Maroje Lang

\section{EDITOR}

Romana Sinkovic

The views expressed in this paper are not necessarily the views of the Croatian National Bank. Those using data from this publication are requested to cite the source.

Any additional corrections that might be required will be made in the website version.

ISSN 1334-0131 (online) 
CROATIAN NATIONAL BANK

WORKING PAPERS W-47

Are Sovereign Credit Ratings Overrated?

Davor Kunovac and Rafael Ravnik 



\title{
Are sovereign credit ratings overrated?*
}

\author{
Davor Kunovac ${ }^{\dagger}$ and Rafael Ravnik ${ }^{\ddagger}$
}

\begin{abstract}
In this paper we examine the relevance of changes in sovereign credit rating for the borrowing cost of EU countries. Our results indicate that discretionary credit rating announcements are only of limited economic importance for the borrowing cost of these countries. It seems that rating agencies do not reveal important new information to financial markets, in addition to that already contained in the underlying fundamentals. Hence, given the sentiment in financial markets, the borrowing cost of a country can only be reduced by improving macroeconomic and fiscal fundamentals.
\end{abstract}

Keywords: Sovereign credit ratings, borrowing cost, macroeconomic and fiscal fundamentals

JEL classification: G14, G24, H63, E62

\footnotetext{
${ }^{*}$ The opinions expressed in this paper are those of the authors and do not necessarily represent the official views of the Croatian National Bank. The authors would like to thank the anonymous referee, Ivan Zilic, Velimir Sonje, Marina Tkalec, as well as Nauro Campos, Ricardo Lago and other participants of the 22nd Dubrovnik Economic Conference and the 7th Croatian National Bank Economic Workshop. This paper is submitted for publication in the Comparative Economic Studies Symposium of the 22nd Dubrovnik Economic Conference.

${ }^{\dagger}$ davor.kunovac@hnb.hr

${ }_{\ddagger}^{\ddagger}$ rafael.ravnik@hnb.hr
} 


\section{Introduction and motivation}

Frequent sovereign rating downgrades received a huge amount of public attention during the recent European sovereign debt crisis. The news media as well as policymakers have routinely suggested that credit rating announcements strongly affect the borrowing cost of a country. This is mainly based on the assumption that credit rating agencies may reveal to financial markets important information about creditworthiness of a debt issuer, beside that already contained in macroeconomic fundamentals. In this paper we challenge that presumption and examine the relevance of changes in sovereign credit rating for the borrowing cost of EU (European Union) countries. In other words, we examine whether announcements of rating agencies may affect the price of external borrowing of European countries. We also analyze whether financial markets ground their decisions on the same information set as rating agencies, implying that their announcements have only limited importance for financial markets. The answers to the questions asked may help to inform the discussion on the importance of sovereign credit ratings for the borrowing cost of countries of the European Union.

The analysis conducted in this paper works out the thesis that it is a priori unclear whether the improvement of the credit rating automatically causes a decline in government bond yields of a country. Usually we expect that financial markets and rating agencies largely base their decision on the same set of publicly available macroeconomic and fiscal indicators, such as public debt and deficit, GDP growth or unemployment rate. In such a case a change in the credit rating does not provide any new information to financial markets,

pointing to the absence of asymmetric information between the state as the debt issuer and investors. Moreover, in case the information set on which the agencies base their decision is exactly equal to that of market participants, rating changes would not affect government bond yields at all because efficient markets would have already absorbed (priced in) such information in the price of the debt. The credit rating per se in such a case does not have a dominant influence on the borrowing cost - it is the underlying economic fundamentals that determine the borrowing cost in the long run. Therefore, given the sentiment in financial markets, the government's borrowing cost can only be reduced by improving macroeconomic and fiscal fundamentals. Any increase in the credit rating may then follow only as a natural consequence of these improvements. However, if, on the other hand, information sets of rating agencies and market participants differ significantly, changes of credit ratings may surprise the financial markets and in this way directly affect the government bond yields. In such a case credit ratings are truly informative and rating announcements now reveal new information to financial markets, in addition to that already contained in economic fundamentals. Only for 
such a case of the presence of substantial asymmetric information it makes sense to consider the increase in the credit rating as a precondition for lower government bond yields. In order to gain a better insight into the mechanism according to which the main rating agencies can affect the borrowing cost of European countries we conduct an analysis based on the four steps we summarize below.

In the first step we estimate the direct impact of sovereign credit rating changes on the borrowing cost of European countries. For this purpose we conduct an event study analysis in order to estimate the reaction of EU members CDS (Credit Default Swap) spreads to changes in credit ratings. Our focus is on the announcements of the big three rating agencies: Standard \& Poor's, Moody's and Fitch. The analysis suggests that the reaction of CDS spreads on rating downgrades is statistically significant but rather mild (around 10 basis points over the first two days), while the reaction to rating upgrades is not significant at all. Moreover, the total new information is completely absorbed in the price within the first two days following the rating announcement. However, it turned out that the reaction largely depends on the current level of the respective country's rating at the day when the rating change is announced. The reaction is the strongest following downgrades that lead to an asset class shift from the investment into the junk category (around 29 basis points). In addition, the market reaction is somewhat stronger for the first downgrade into the junk category (approximately 36 basis points), while subsequent rating downgrade announcements by other agencies normally do not lead to a significant reaction by the financial markets. The stronger reaction of sovereign spreads to the downgrade into the junk category may, at least partially, be explained by administrative and regulatory restrictions. For instance, institutional investors that are prevented by regulatory constrains from investing into securities of certain rating categories only, may rebalance their portfolio and thereby decrease demand for junk-rated government bonds and can thus directly affect their yield. However, one has to be cautious when using these results in order to draw conclusions about the importance of the estimated impact of a downgrade for individual countries. An increase by 10 basis points would clearly be visible for German or Finish spreads whose variability is very low. On the other hand, given the average variability of spreads in the entire sample the estimated impact may be considered negligible.

The results of the first part of the analysis may lead to a preliminary conclusion that rating agencies do not reveal important new information on the credibility of the debt issuer to the market participants, where the only exception is downgrading a country into the junk category. These results suggest that agencies base their decisions, to a large extent, on the information that is already absorbed in the borrowing cost. In order to carry out a formal verification of this preliminary conclusion further analysis was conducted in order to examine 
the way in which the main rating agencies determine the rating of EU member states. After that we also analyze the information set of the bond market participants.

The second step of this paper studies how the three leading rating agencies determine the credit ratings of EU member states. In other words, here we try to approximate the information set used by credit rating agencies when deciding on the credit rating of a country. For this purpose we project credit ratings onto the usual set of publicly available macroeconomic and fiscal indicators. Based on the estimated relationships we decompose the credit ratings into two parts: i) a systematic part labelled as credit rating implied by fundamentals (i.e. the estimated regression fit) and ii) a discretional part that is unexplained by fundamentals (residual of the estimated regression). The unexplained part approximates discretionary actions of rating agencies - specific information on the rating of a country that does not follow the dynamics of fundamentals in a systematic way. The main findings of this step of the analysis suggest that the estimated systematic part is able to capture the dynamics of the true credit rating very well. Around $90 \%$ of ratings implied by fundamentals were equal or one notch different from the actual ratings.

In the third step we analyze whether rating agencies reveal any new information to financial markets that has not yet been absorbed (priced in) in the borrowing cost of a country. In other words, our objective here is to isolate the informational contribution of the credit ratings to CDS market in addition to that already contained in the economic fundamentals. For that purpose we decompose the CDS spreads into three components: i) the contribution of economic fundamentals captured by the previously estimated systematic part of the credit rating, ii) contribution of the discretional part (contribution of the residual) and iii) contribution of global risk aversion. The mentioned decomposition allows us to assess the relative importance of discretionary rating agency actions for the borrowing cost of the analyzed countries. Our results suggest that fundamentals, along with the global risk aversion, are the most important determinants of CDS spreads of European countries. On the other hand, the discretional part of the credit rating explains only a small portion of the variation in CDS spreads.

In the final step of our analysis we estimate so-called market implied ratings and compare them with the corresponding observed credit ratings. It is important to note that the ranking of a set of countries by their credit rating is not necessary in line with their ranking by CDS spreads. One explanation of this inconsistency could be attributed to the fact that rating agencies are prudent in their approach to rating revisions which means that they neglect shortterm fluctuations in economic fundamentals. On the other hand, market participants tend to react immediately to changes in the underlying economic fundamentals. The described difference in behavior between the rating agencies and the market participants is noticeably 
confirmed by our results. More precisely, the estimated market implied ratings are able to anticipate almost all observed rating changes well in advance. In other words, rating changes are significantly lagging behind CDS spreads. For example, market participants placed Croatia, Hungary and Portugal into the junk category more than two years before rating agencies downgraded these countries into junk.

The entire analysis clearly points to the conclusion that the autonomous, discretional impact of rating announcements on the borrowing cost for EU member states is significant in the statistical sense. However, the economic importance of this impact is rather limited. On the other hand, our results, in line with the related literature suggest that macroeconomic fundamentals, in addition to global risk aversion, are the dominant determinants of the borrowing cost of European countries. The analysis thus leads to the conclusion that the importance of rating agencies for the borrowing cost is probably overrated by the general public and that, under given financial market conditions, only an improvement in the underlying macroeconomic fundamentals can substantially lower the borrowing cost of a country. Our results are robust and consistent across all methodological approaches used in this paper.

\subsection{Selected related literature}

The existing empirical literature on sovereign credit ratings and government's borrowing cost that is relevant for our paper is quite extensive and analyses a wide array of specific questions. The results related to the impact of credit ratings on government's borrowing costs are still ambiguous.

The literature available thus far relies heavily on the event study analysis and uses daily frequency data in order to examine the importance of rating agencies. The event study analysis to test the reaction of spreads of different countries to changes in their credit ratings was, for instance, carried out in Cantor and Packer (1996), Afonso et al (2012), Aizeman et al (2013), Torres (2004), Özmen, Yaşar (2015) and Kaminsky, Schmukler (2002). The results differ in terms of intensity and significance of the reaction, as well as in terms of the time of absorption. However, consensus was achieved regarding the asymmetry of the estimated reactions, which means that rating downgrades are on average followed by a stronger market reaction in comparison to rating upgrades. Additionally, some of the listed papers and Jaramillo and Tejada (2011), who are using a slightly different methodology, estimate stronger-than-average market reaction when a country's rating is downgraded from investment into the speculative (junk) category.

On the other hand, the present paper is related to research on determinants of credit ratings. Some of these papers include Cantor and Packer (1996), Feri, et al (1999), Afonso 
(2003), Bissoondoyal-Bheenick (2004), Afonso et al (2009) and Gärtner et al (2011). These papers generally deal with the issue of finding appropriate rating determinants and the accuracy of rating forecasts, while the results are not put into the context of their impact on the borrowing cost. The only exception is Gärtner et al (2011), where similarly as in the present paper, a decomposition of spreads into two basic factors was made: the part explained by fundamentals and unexplained part which the authors interpret as the discretionary actions of rating agencies. This was also done in two steps: regressing credit ratings on a broad set of explanatory variables and after that a decomposing spreads into the part explained by fundamentals and the unexplained or discretional part. However, the mentioned paper may have some shortcomings regarding the interpretation of results. In the first part of the analysis the authors include government bond yields in the set of regressors which means that the resulting estimates of this paper may be interpreted as ratings implied by fundamentals and market. It therefore becomes impossible to disentangle what part of the information is common to the market and rating agencies and what part represents the discretionary actions of the rating agency. Moreover, the authors are only emphasizing the statistical significance of the estimated coefficients without discussing the economic importance of the credit rating in comparison to the importance of macroeconomic fundamentals and global risk factors. Similar analyses are conducted in Eichengreen, Mody (1998) and Dell'Ariccia et al (2006) where one could address the same critiques as mentioned above. Afonso et al (2015) also analyzed to what extent rating agencies influence the spread of European countries, in addition to information already contained in the fundamentals. For that purpose the authors regressed sovereign spreads on a set of economic fundamentals and compared the results with an extended regression that includes the average credit rating as an additional regressor. Their sample includes only ten selected European countries. The authors find a statistically significant relationship between the credit rating and spreads. However, they conclude that including the credit rating improve the fit of the regression only by a negligible amount.

Cavallo et al (2012) are conducting an empirical analysis of the importance of credit rating agencies for a wide set of emerging market economies. They use high-frequency data in order to examine whether credit ratings contain new information for financial market variables after controlling for sovereign bond spreads and economic fundamentals. By using different methodological approaches the authors conclude that ratings indeed add some additional information. However, similar as for the papers listed above, it is not clear how big this informational contribution is relative to the information contained in economic fundamentals and spreads. In other words, the economic importance of rating agencies is not assessed in this paper. 
The present paper builds on the existing literature on the importance of credit ratings in several ways. First it focuses on a wide set of EU countries during the sovereign debt crises which was characterized by a large number of sovereign rating downgrades along with significant increases in government bond yields. This is interesting from policymakers prospective since both fiscal and monetary policy actions during that period were motivated by mounting spreads in the financial markets. It is therefore of crucial importance to understand which role was played by the rating agencies in this borrowing cost increase. Second, we are moving the discussion from statistical significance towards economic significance by providing a decomposition of spreads to the contribution of credit ratings and contributions of other relevant factors. By doing so, we are able to make a clear distinction between the contribution of fundamentals, global factors and the credit rating itself. Third, this paper is to our knowledge the first attempt of estimating market implied ratings for sovereign, rather than corporate, spreads.

\section{Are credit rating announcements affecting financial markets?}

In this section we quantify the direct impact of credit rating announcements on the borrowing cost of EU countries. ${ }^{1}$ When the information set on which rating agencies base their decision is equivalent to the information set of the market participants, the market will not react significantly to credit rating announcements. On the other hand, if the rating announcement comes as a surprise to the market participants, they will react to the mentioned announcement and absorb this new information into the respective government bond yield. In order to examine the mentioned surprise effect, we estimate the reaction (and time of absorption) of spreads to sovereign rating announcements by conducting an event study analysis on a set of European countries.

Data The analysis uses a panel of daily data for the period from January 2007 to September 2015 for 23 EU member states (54480 daily observations). ${ }^{2}$ The dependent variable is represented by CDS spreads of these EU countries. ${ }^{3}$

\footnotetext{
${ }^{1}$ The analysis carried out in this chapter largely follows Kunovac (2012) and CNB (2012).

${ }^{2}$ This includes the following countries: Croatia, Austria, Belgium, Bulgaria, Czech Republic, Denmark, Estonia, Finland, France, Italy, Latvia, Lithuania, Hungary, Germany, Netherlands, Poland, Romania, Slovenia, Slovakia, Sweden, Spain and the United Kingdom. We excluded those EU countries for which data on comparable CDS spreads was not available.

${ }^{3}$ In this paper CDS spreads have been used as a proxy variable of the country risk premium due to the unavailability of a comparable series of bond yield spreads for all analyzed countries. However, the correlation
} 
In order to identify rating changes, we construct two dummy variables, one identifying the days when upgrades were observed while the other identifies the days when rating downgrades were observed. ${ }^{4}$ The estimated parameters corresponding to these dummy variables measure the impact of rating changes on the CDS spreads. In order to estimate the time needed for absorption of rating changes into spreads, we also add the lagged dummies to our specification. Additionally, we include three control variables: the volatility index as an indicator of global risk aversion, ${ }^{5}$ the common factor of European CDS spreads as the indicator of common dynamics in the market of European government bonds and stock market indices for each individual country. The common factor of European CDS spreads is estimated by the principal component analysis and it controls for possible spillover and contagion effects between EU countries, as well as for other common dynamics. This variable plays an important role in capturing the sharp increase in spreads observed during the European sovereign debt crisis which was to a large extent explained by these common factors (Kunovac, 2013). We additionally include stock market indices in this analysis in order to measure country specific business cycles at daily frequency. The choice of this variable can be justified by standard economic theory, which postulates that today's stock prices reflect the discounted future cash flows (i.e. dividends) related to that stock. Moreover, expectations about future business cycle dynamics are positively correlated with expectation about future dividends. Consequently, one can expect that today's stock prices are determined by expectations about the future business cycle. For instance, if the market expects a drop in real activity in the near future, it also expects weaker business results of companies in the market and consequently lower capital income in the form of smaller dividends. Thus, the ultimate consequences of the expected drop in real activity are decreasing stock prices. It is important to include these stock indices in our analysis in order to control for possible pro-cyclicality in rating announcements. Omitting these variables could lead to biased estimates of the effect of rating changes on spreads if rating agencies are indeed systematically

between CDS spreads and bond spreads is very high both at daily frequency as well as at lower frequencies. In addition, Kunovac (2013) has shown that results on the determinants of CDS spreads and spreads of generic bond yields are equal to a great extent. Moreover, in theory CDS and bond spreads should have very similar dynamics. Indeed, suppose that $i$ is the yield of a one-year bond, $r$ is the yield of an equivalent non-risky instrument and $c d s$ is the pertaining credit risk insurance premium for the bond. Then the purchase of the insured portfolio that consists of this bond and insurance in the form of CDS is approximately equal to the purchase of a risk-free bond and the following holds: $i-c d s=r$. From this it follows that $c d s=i-r$, which means that CDS and bond spreads are in theory equivalent. In practice there are a number of reasons why CDS and bond spreads diverge (De Wit, 2006) but generally there is a high correlation between them.

${ }^{4}$ There are currently 76 rating agencies in the world (Bach, 2014). However, the focus is on the largest three agencies (Standard \& Poor's, Fitch i Moody's) that cover the widest spectrum of debt securities. Therefore, this paper analyses only the three mentioned rating agencies.

${ }^{5}$ The measure of risk aversion included in this analysis is the volatility index on European stock exchanges (Euro Stoxx 50 Volatility Index). 
downgrading (upgrading) countries during economic downturns (upturns).

Model The spreads and all three control variables are included in the equation in first differences, and fixed effects are additionally assumed in order to control for unobserved heterogeneity among countries included in the sample. The specification of the equation is given below, where $D_{i, t-j}$ represents the dummy variable for rating upgrades (downgrades) of a country $i$, in period $t-j, \eta_{i, t}$ the fixed effects, $\log \left(S T O C K_{i, t}\right)$ the logarithm of the stock index, $P C_{t}$ the common factor of CDS spreads, $V X_{t}$ represents the measure of risk aversion, and $\epsilon_{i, t}$ the normally distributed error with zero expectation.

$$
\begin{aligned}
\Delta C D S_{i, t} & =\alpha_{0}+\eta_{i, t}+\sum_{j=0}^{2} \beta_{j} D_{i, t-j}+\alpha_{1} \Delta \log \left(\operatorname{STOCK}_{i, t}\right)+ \\
& +\alpha_{2} \Delta P C_{t}+\alpha_{3} \Delta V X_{t}+\epsilon_{i, t}
\end{aligned}
$$

Two models have been estimated where the variable $D_{i, t-j}$ represents two different events a rating upgrade and a rating downgrade. In this exercise, no distinction between individual rating agencies is made which means that only one dummy variable for downgrades (and one for upgrades) is used. In other words, we are not looking for potentially heterogeneous market reactions to different rating agencies which is not of crucial importance for our paper. We are rather estimating the average reaction of CDS spreads to all observed credit rating changes. The equations are estimated using the within estimator (fixed effects) according to the Hausman test. The significance levels are based on White robust standard errors.

Results The results in Table 1 show that CDS spreads indeed responded to sovereign rating downgrades in the period under review. Although this reaction was statistically significant, its magnitude was rather low. On average, spreads rose by about 6 basis points on the day of the rating downgrade and by additional 5 basis points the next day. It is noteworthy that markets absorb the overall impact of the rating downgrade within two days which additionally confirms that the price of borrowing in the long run is not determined by actions of rating agencies. ${ }^{6}$

The second column in Table 1 shows the result of the market reaction to rating upgrades. The estimated parameters related to the dummy variables are not statistically significant,

\footnotetext{
${ }^{6}$ For clarity, only the results for the change in the rating on the day of the announcement and for the first two days after the announcement are shown. We also estimated a model with a greater number of lags but further lags were not statistically significant. In addition to rating changes, we estimated a model with outlook changes and this variable (and lags of this variable) was not statistically significant.
} 
Table 1: The impact of rating downgrades/upgrades on CDS spreads

\begin{tabular}{|c|c|c|}
\hline & \multicolumn{2}{|c|}{ CDS } \\
\hline & Rating downgrade & Rating upgrade \\
\hline Intercept & -0.05 & -0.01 \\
\hline & () & () \\
\hline Risk aversion & 0.05 & 0.05 \\
\hline & $(*)$ & $(*)$ \\
\hline CDS common factor & $\begin{array}{l}18.73 \\
(* * *)\end{array}$ & $\begin{array}{l}18.75 \\
(* * *)\end{array}$ \\
\hline Stock prices & $\begin{array}{c}-18.43 \\
(* * *)\end{array}$ & $\begin{array}{c}-18.73 \\
(* * *)\end{array}$ \\
\hline$D_{t}$ & $\begin{array}{l}6.11 \\
(* *)\end{array}$ & $\begin{array}{c}-1.01 \\
()\end{array}$ \\
\hline$D_{t-1}$ & $\begin{array}{l}4.74 \\
(* *)\end{array}$ & $\begin{array}{c}0.15 \\
()\end{array}$ \\
\hline$D_{t-2}$ & $\begin{array}{c}0.92 \\
()\end{array}$ & $\begin{array}{c}-2.16 \\
()\end{array}$ \\
\hline Adjusted $\mathrm{R}^{2}$ & 0.31 & 0.31 \\
\hline S.E. of regression & 9.64 & 9.65 \\
\hline Number of events & 115 & 39 \\
\hline F-statistic & $\begin{array}{l}825.2 \\
(* * *)\end{array}$ & $\begin{array}{l}820.6 \\
(* * *)\end{array}$ \\
\hline
\end{tabular}

Note: Dependent variables are daily changes in CDS spreads. The symbols ***, ${ }^{* *}$ and $*$ denote statistical significance at the $1 \%, 5 \%$ and $10 \%$ level, based on the White robust standard error estimator.

suggesting that CDS spreads in our sample did not exhibit systematic reactions to positive rating news.

The results given in Table 1 quantify the impact of agency announcements on spreads for a relatively large and heterogeneous group of countries. Therefore, we have to be cautious when using these results in order to draw conclusions about the expected impact of a downgrade for individual countries. In other words, it is not a priori clear whether the impact of a rating change on borrowing costs is linear, i.e. whether it affects all countries in the same way regardless of their current rating. The reaction of the financial markets might be stronger following downgrades into the junk category in comparison to the average reaction estimated above. Such a potentially stronger reaction can be explained by regulatory restrictions for some of the market participants. For instance, institutional investors that are prevented by regulatory constrains from investing into securities of certain rating categories may decrease their demand for low-rated government bonds and can thus directly affect their yield. 
Table 2: The impact of rating downgrades on CDS spreads for different rating categories

\begin{tabular}{lccc}
\hline \hline & \multicolumn{3}{c}{ CDS } \\
\cline { 2 - 4 } & Junk entry & Junk ratings & Investment ratings \\
\hline Intercept & -0.01 & -0.40 & 0.02 \\
Risk aversion & () & $(* *)$ & () \\
& 0.04 & -0.02 & 0.06 \\
CDS common factor & $(*)$ & () & $(*)$ \\
& 19.00 & 33.57 & 17.51 \\
Stock Prices & $(* * *)$ & $(* * *)$ & $(* * *)$ \\
& -24.24 & -93.17 & -17.20 \\
$D_{t}$ & $(* * *)$ & $(* * *)$ & $(* * *)$ \\
& 0.38 & 1.55 & 3.51 \\
$D_{t-1}$ & () & () & () \\
& 28.60 & 16.62 & $(* *)$ \\
$D_{t-2}$ & $(* *)$ & $(* *)$ & -0.42 \\
& 3.18 & 8.33 & () \\
\hline Adjusted R & () & $(* *)$ & 0.34 \\
S.E. of regression & 0.33 & 0.34 & 5.88 \\
Number of events & 6.61 & 11.23 & 97 \\
F-Statistic & 15 & 23 & 847.2 \\
& 907.2 & 255.8 & $(* * *)$ \\
\hline Note: Dep & $(* * *)$ & $(* * *)$ & ( \\
\hline
\end{tabular}

Note: Dependent variables are daily changes in CDS spreads. The symbols $* * *$, $* *$ and $*$ denote statistical significance at the $1 \%, 5 \%$ and $10 \%$ level, based on the White robust standard error estimator.

In order to estimate such non-linear effects we constructed a dummy variable which identifies only those rating changes that lead to rating downgrades from the investment into the speculative category. The first column of Table 2 shows the results of the model that includes the mentioned dummy variable. These results suggest that the reaction of CDS spreads on rating downgrades in this category is greater compared to the aggregate results in Table 1. CDS spreads declined on average by 29 basis points on the day of the downgrade, which is almost three times stronger than the average reaction. Such a stronger reaction can, at least partially, be explained by the earlier mentioned mechanism of the decrease in demand for bonds in the speculative category.

We constructed an additional equation in order to estimate the reaction of CDS spreads to rating downgrades only for those countries that already are in the junk category. The results are shown in the second column in Table 2. The estimated parameters suggest that the average reaction of CDS spreads for these countries amounts to around 25 basis points 
within two days from the rating downgrade, which is slightly less than the average reaction to downgrades from the investment into the junk category. On the other hand, the reaction of CDS spreads to rating downgrades for countries that are in the investment category (Table 2 , third column) is much weaker (only 5 basis points within two days).

The results above show that the strongest CDS reaction is related to the entry into the junk category. Our next step is to examine the difference in CDS reactions with respect to the chronological order of the entry to junk category. In other words, the aim is to analyze whether the reaction to the first downgrade from the investment into the junk category is different in comparison to the following downgrades. For that purpose we constructed three dummy variables, where the first identifies the day on which a country's rating was downgraded to speculative category for the first time, while the second and the third variable identify the days on which the remaining two rating agencies placed this country in the speculative category. The estimated parameters for this model are shown in Table 3 . The strongest market reaction is found for the first downgrade into the junk category (36 basis points). The reaction to the second downgrade is much weaker (13 basis points), while the reaction of the market to the third downgrade is not significant at all. Note, however, that these results are obtained on a sample with a very small number of events.

Again, it is important to note that the interpretation of the above results for individual countries require a certain degree of caution. For example, the reaction of CDS spreads to rating downgrades into the junk category may be weaker for a country that is already perceived by financial markets as a country that belongs into the junk category. On the other hand, those countries that the markets place in the investment category until the very moment of the downgrade will face a stronger reaction. Thus, for example, the CDS spread for Croatia increased by only 13 basis points within two days from the first (S\&P's) downgrade into the junk category. This relatively weak reaction of CDS spreads to the mentioned downgrade may lead to the conclusion that markets had already perceived Croatia as a junk category country such that the downgrade itself did not represent important news for the market participants. On the other hand, the reaction of Latvias CDS spread amounted to over 40 basis points within two days after its downgrade into junk, which can be considered a market surprise.

The results presented in this section indicate that the reaction of CDS spreads to credit rating downgrades is on average mild and that there is no reaction at all to rating upgrades. However, downgrades from the investment into the junk category may represent new information for market participants and the reaction of CDS spreads on such downgrades can therefore amount to around 30 basis points. 
Table 3: The impact of rating downgrades on CDS spreads with respect to the downgrading order

\begin{tabular}{lccccccccccc}
\hline \hline Risk & CDS factor & Stock prices & $D_{1, t}$ & $D_{1, t-1}$ & $D_{1, t-2}$ & $D_{2, t}$ & $D_{2, t-1}$ & $D_{2, t-2}$ & $D_{3, t}$ & $D_{3, t-1}$ & $D_{3, t-2}$ \\
\hline 2.17 & 18.70 & -16.61 & -6.74 & 36.03 & 6.89 & 13.52 & 7.22 & -2.46 & 1.28 & 21.02 & 4.05 \\
$(* *)$ & $(* * *)$ & $(* * *)$ & () & $(* *)$ & () & $(* *)$ & () & () & () & () & () \\
\hline
\end{tabular}

Note: The dependent variable is the daily changes in CDS spreads. The symbols $* * *,{ }^{* *}$ and ${ }^{*}$ denote statistical significance at 1\%, $5 \%$ and $10 \%$ level, based on the White robust standard error estimator. $D_{1, t}, D_{2, t}, D_{3, t}$ represent the first, second and third downgrade to junk category. Variable $D_{1, t}$ includes 7 events, $D_{2, t} 5$ events, while $D_{3, t}$ includes 3 events.

\section{Determinants of credit ratings}

The results of the previous section suggest that there is no significant information asymmetry between governments as debt issuers on one side and investors in the financial market on the other side. In other words, it seems that, with the exception of the entry to the junk category, agencies do not reveal important new information about the creditworthiness of a debt issuer to the financial markets. We could therefore conclude that rating agencies base their decisions, to a large extent, on the information that is already absorbed in the borrowing cost. In order for this preliminary conclusion to be checked effectively, in this chapter we explore how the three leading rating agencies determine the ratings of EU countries. Afterwards in the following two chapters we analyze the information set of the bond market participants.

\subsection{Empirical estimation of credit rating determinants}

In this chapter, the analysis is based on simple linear panel data models used to estimate the impact of a series of key macroeconomic and fiscal indicators on credit ratings of EU member states for the three leading rating agencies. As already mentioned earlier, rating agencies base their risk assessment of a country on a wide spectrum of economic, fiscal and political factors, but also on additional qualitative evaluations. ${ }^{7}$ In order to estimate the relationship between the credit ratings of EU member states and their potential determinants we project credit ratings of EU countries onto the usual set of publicly available macroeconomic and fiscal indicators.

\footnotetext{
${ }^{7} \mathrm{~A}$ detailed description of the relevant indicators that rating agencies take into account when deciding on credit ratings of a country is given in IMF (2010) as well as Standard and Poor's (2014).
} 
Data Similar to Gärtner et al (2011), and Cantor and Parker (1996) the following rating determinants were used in this chapter: ${ }^{8}$

- Real GDP growth rate (annual rate of change)

- Public debt (general government debt-to-GDP ratio)

- Budget surplus (overall budget balance of the general government, expressed as a ratio to GDP)

- Interest payments (general government interest payments, expressed as a ratio to GDP)

- Inflation rate (annual rate of change in the HICP)

- Unemployment rate (ILO methodology)

- Economic freedom index

In order to estimate the relationship between the determinants listed above and the credit ratings of EU countries we use four different linear models: one model for each of the three rating agencies and one model for the average rating. The ratings are transformed into a numerical scale from the lowest rating marked by number 1 (below $C C C+$ for $\mathrm{S} \& \mathrm{P}$ and Fitch, and below Caa1 for Moody's) up to the highest rating marked by number 17 (AAA for S\&P and Fitch and Aaa for Moody's) while the lowest rating in the investment category is marked by number 8. We use quarterly data on the sample 2007Q1-2015Q3 for the same set of countries as in the previous chapter which amounts to 805 observations.

Model We estimate the following linear panel regression for each agency as well as for the average rating: ${ }^{9}$

$$
R_{i, t}=c+\eta_{i, t}+\beta_{1}^{\prime} X_{i, t}+\varepsilon_{i, t}
$$

\footnotetext{
${ }^{8}$ The data source for the index of economic freedom is the Heritage Foundation web site, while all other data has been downloaded from the Eurostat database. All regressors enter the equations as one-year moving averages in order to remove short-run cyclical fluctuations.

${ }^{9}$ It is noteworthy that rating agencies base their decisions, to some extent, on the basis of expectations (forecasts) of macroeconomic fundamentals. In order to verify whether the link between a country's rating and fundamentals is different for the case of observed fundamentals in comparison to the case of forecasted fundamentals, we estimated these relationships for both cases on a narrower set of European countries for which a long enough series of forecasts was available. In doing this, we used the macroeconomic projections of the European Commission. The results obtained for the model with forecasted fundamentals are in line with the results obtained for the model with observed fundamentals.
} 
where $R_{i, t}$ is the credit rating assigned by the respective agency for period $t$ and country $i, X_{i, t}$ represents the determinants listed earlier for country $i$ and period $t, c$ represents the common intercept, $\eta_{i, t}$ potential fixed effect, $\beta_{1}^{\prime}$ is the vector of unknown parameters, and $\varepsilon_{i, t}$ represents a normally distributed residual with zero expectation. Besides the mentioned baseline specification, we estimated an additional specification, expanded by the term $\beta_{2}^{\prime} D_{80} X_{i, t}$, that is, an interaction dummy variable $D_{80}$ which equals 1 if the respective country had a public debt above $80 \%$ of GDP in the given period. This interaction dummy variable allows us to estimate potential non-linearity in the reaction function of rating agencies. The $80 \%$ debt level is interesting for the analyzed sample due to the fact that several European countries have exceeded this threshold during the sovereign debt crisis and therefore one can expect that investors and rating agencies have analyzed the risk of these highly indebted countries more carefully during the mentioned crisis.

It should be noted that it is not a priori clear how to model the heterogeneity among the EU member states - by using fixed effects or random effects? For this purpose we estimated several alternative specifications of equation 2 with selective inclusion of fixed and random effects. The main conclusion of the conducted analysis is that models with random effects that include the average GDP per capita as an additional regressor, can successfully replicate the results of the fixed effects model. The estimated parameters, in-sample-fit and respective residuals are thus to a large extent in line with those obtained from the fixed effects model. ${ }^{10}$ The results obtained, as has been expected, suggest that the level of economic development (GDP per capita) largely determines the differences between rating levels among the analyzed countries. ${ }^{11}$ For this reason, it is not crucial for the objective of this paper whether the main specification linking the ratings of EU member states and fundamentals will include fixed effects or, similarly, whether the heterogeneity between countries will be represented by GDP per capita in a random effect model. Nevertheless, bellow we carried out an analysis with fixed effects due to the Hausman test results shown in Table 4. Additionally, the significance levels are based on White robust standard errors.

\footnotetext{
${ }^{10}$ The estimated parameters for the said alternative specifications for the average rating are shown in Table 9 of the Appendix. The residuals and the model fit are not shown due to space constraints and are available on request.

${ }^{11}$ Columns V and VI of Table 9 in the Appendix show the estimated parameters of the specification which, in addition to the level of the average GDP per capita, include the square of this variable. The purpose of these specifications is to analyze the potential non-linear relationship between the GDP per capita and the credit rating. The estimated fit and the respective residuals for this specification is to a large extent equivalent to those from the fixed effects model, while the heterogeneity among countries is almost fully described by the quadratic specification used. In addition, the estimated values of other parameters are in line with those obtained from the fixed effects model.
} 
Table 4: Hausman test for credit rating determinants equations

\begin{tabular}{lccccccccc}
\hline \hline & \multicolumn{4}{c}{ Baseline Model } & & \multicolumn{3}{c}{ Nonlinear Model } \\
\cline { 2 - 3 } & SP & Moody's & Fitch & Average & & SP & Moody's & Fitch & Average \\
\hline Chi-squared statistic & 141.6 & 218.3 & 199.2 & 194.4 & & 130.8 & 208.3 & 168.4 & 182.3 \\
P - Value & 0.00 & 0.00 & 0.00 & 0.00 & & 0.00 & 0.00 & 0.00 & 0.00 \\
\hline
\end{tabular}

Results The results of the estimated specifications with fixed effects are shown in Table 5, where each column represents the estimated parameters for the corresponding rating agency and for the average rating. The first four columns refer to the baseline specification, while the last four columns are related to the non-linear specification which includes the interaction dummy variable described earlier. When interpreting our results one should bear in mind that the main objective of this analysis was not to estimate and interpret individual model elasticities. Therefore the estimated specification contains a relatively large number of correlated regressors which raises the issue of multicollinearity. However, the primary objective of our analysis is the aggregate influence of fundamentals on rating levels which was the reason we chose such a wider set of regressors.

The estimated parameters for the baseline specification suggest that the credit ratings are well described by the used fundamentals. More precisely, the majority of parameter estimates is statistically significant, with expected signs, a relatively good fit and with standard errors of regressions not exceeding one notch. For instance, the parameter related to public debt is negative, as expected, which means that higher levels of public debt are, on average, related to lower credit ratings. The estimated values of this parameter lie within the range of -0.07 to -0.05 , suggesting that rating upgrades by one notch are, on average, associated with the reduction of debt-to-GDP ratio by 14 to 19 percentage points, everything else being equal. On the other hand, the sign of the estimate corresponding to the budget balance is rather unexpected - results suggest that higher surpluses or lower deficits are associated with lower credit ratings. However, one should take into account that the two mentioned variables (public debt and deficit) contain related information on the state of public finances and are therefore strongly correlated, which can be one of the explanations for this unexpected sign.

The parameters corresponding to the unemployment rate and GDP growth have expected signs and are statistically significant for all three agencies, as well as for the average rating. The parameters related to interest payments and inflation have the expected sign and are also statistically significant for all agencies. The sign of the parameter corresponding to the economic freedom index is positive for all four baseline models. This is in line with our expectations because countries with a greater degree of economic freedom have, on average, 
Table 5: Determinants of sovereign credit ratings

\begin{tabular}{|c|c|c|c|c|c|c|c|c|}
\hline & \multicolumn{4}{|c|}{ Baseline Model } & \multicolumn{4}{|c|}{ Nonlinear Model } \\
\hline & SP & Moody's & Fitch & Average & SP & Moody's & Fitch & Average \\
\hline Intercept & $\begin{array}{l}16.26 \\
(* * *)\end{array}$ & $\begin{array}{c}9.68 \\
(* * *)\end{array}$ & $\begin{array}{l}13.88 \\
(* * *)\end{array}$ & $\begin{array}{l}12.06 \\
(* * *)\end{array}$ & $\begin{array}{l}16.41 \\
(* * *)\end{array}$ & $\begin{array}{l}10.12 \\
(* * *)\end{array}$ & $\begin{array}{l}14.08 \\
(* * *)\end{array}$ & $\begin{array}{l}12.12 \\
(* * *)\end{array}$ \\
\hline Gov. debt & $\begin{array}{l}-0.05 \\
(* * *)\end{array}$ & $\begin{array}{l}-0.07 \\
(* * *)\end{array}$ & $\begin{array}{l}-0.05 \\
(* * *)\end{array}$ & $\begin{array}{l}-0.05 \\
(* * *)\end{array}$ & $\begin{array}{c}-0.01 \\
(*)\end{array}$ & $\begin{array}{l}-0.04 \\
(* * *)\end{array}$ & $\begin{array}{c}0.00 \\
()\end{array}$ & $\begin{array}{l}-0.01 \\
(* * *)\end{array}$ \\
\hline Budget balance & $\begin{array}{l}-0.06 \\
(* * *)\end{array}$ & $\begin{array}{l}-0.10 \\
(* * *)\end{array}$ & $\begin{array}{l}-0.06 \\
(* * *)\end{array}$ & $\begin{array}{l}-0.06 \\
(* * *)\end{array}$ & $\begin{array}{c}0.02 \\
()\end{array}$ & $\begin{array}{c}-0.03 \\
()\end{array}$ & $\begin{array}{c}0.01 \\
()\end{array}$ & $\begin{array}{c}0.01 \\
()\end{array}$ \\
\hline Unemployment & $\begin{array}{l}-0.22 \\
(* * *)\end{array}$ & $\begin{array}{l}-0.13 \\
(* * *)\end{array}$ & $\begin{array}{l}-0.16 \\
(* * *)\end{array}$ & $\begin{array}{l}-0.17 \\
(* * *)\end{array}$ & $\begin{array}{l}-0.17 \\
(* * *)\end{array}$ & $\begin{array}{l}-0.08 \\
(* * *)\end{array}$ & $\begin{array}{l}-0.13 \\
(* * *)\end{array}$ & $\begin{array}{l}-0.12 \\
(* * *)\end{array}$ \\
\hline GDP growth & $\begin{array}{l}0.05 \\
(* *)\end{array}$ & $\begin{array}{c}0.04 \\
(* * *)\end{array}$ & $\begin{array}{c}0.06 \\
(* * *)\end{array}$ & $\begin{array}{c}0.05 \\
(* * *)\end{array}$ & $\begin{array}{l}0.02 \\
(* *)\end{array}$ & $\begin{array}{c}0.01 \\
()\end{array}$ & $\begin{array}{c}0.04 \\
(* * *)\end{array}$ & $\begin{array}{l}0.02 \\
(* *)\end{array}$ \\
\hline Interest payments & $\begin{array}{l}-0.49 \\
(* * *)\end{array}$ & $\begin{array}{l}-1.05 \\
(* * *)\end{array}$ & $\begin{array}{l}-0.79 \\
(* * *)\end{array}$ & $\begin{array}{l}-0.84 \\
(* * *)\end{array}$ & $\begin{array}{l}-0.75 \\
(* * *)\end{array}$ & $\begin{array}{l}-1.08 \\
(* * *)\end{array}$ & $\begin{array}{l}-0.95 \\
(* * *)\end{array}$ & $\begin{array}{l}-0.99 \\
(* * *)\end{array}$ \\
\hline Inflation & $\begin{array}{l}-0.14 \\
(* * *)\end{array}$ & $\begin{array}{l}-0.09 \\
(* * *)\end{array}$ & $\begin{array}{l}-0.12 \\
(* * *)\end{array}$ & $\begin{array}{l}-0.11 \\
(* * *)\end{array}$ & $\begin{array}{l}-0.07 \\
(* * *)\end{array}$ & $\begin{array}{c}-0.02 \\
()\end{array}$ & $\begin{array}{l}-0.06 \\
(* * *)\end{array}$ & $\begin{array}{c}-0.04 \\
(*)\end{array}$ \\
\hline Econ. freedom & $\begin{array}{l}0.04 \\
(* *)\end{array}$ & $\begin{array}{c}0.15 \\
(* * *)\end{array}$ & $\begin{array}{c}0.07 \\
(* * *)\end{array}$ & $\begin{array}{c}0.11 \\
(* * *)\end{array}$ & $\begin{array}{c}0.01 \\
()\end{array}$ & $\begin{array}{c}0.12 \\
(* * *)\end{array}$ & $\begin{array}{c}0.04 \\
(* * *)\end{array}$ & $\begin{array}{c}0.08 \\
(* * *)\end{array}$ \\
\hline Gov. debt*D80 & & & & & $\begin{array}{l}-0.08 \\
(* * *)\end{array}$ & $\begin{array}{l}-0.09 \\
(* * *)\end{array}$ & $\begin{array}{l}-0.08 \\
(* * *)\end{array}$ & $\begin{array}{l}-0.08 \\
(* * *)\end{array}$ \\
\hline Budget balance*D80 & & & & & $\begin{array}{c}-0.08 \\
(*)\end{array}$ & $\begin{array}{c}-0.06 \\
()\end{array}$ & $\begin{array}{c}-0.04 \\
()\end{array}$ & $\begin{array}{c}-0.07 \\
(* *)\end{array}$ \\
\hline Unemployment*D80 & & & & & $\begin{array}{l}-0.13 \\
(* * *)\end{array}$ & $\begin{array}{c}-0.1 \\
(* * *)\end{array}$ & $\begin{array}{c}-0.08 \\
(* *)\end{array}$ & $\begin{array}{l}-0.13 \\
(* * *)\end{array}$ \\
\hline GDP growth*D80 & & & & & $\begin{array}{c}0.03 \\
()\end{array}$ & $\begin{array}{l}0.11 \\
(* *)\end{array}$ & $\begin{array}{c}0.04 \\
()\end{array}$ & $\begin{array}{c}0.06 \\
(*)\end{array}$ \\
\hline Interest payments*D80 & & & & & $\begin{array}{l}0.36 \\
(* *)\end{array}$ & $\begin{array}{c}0.23 \\
()\end{array}$ & $\begin{array}{c}0.00 \\
()\end{array}$ & $\begin{array}{c}0.17 \\
()\end{array}$ \\
\hline inflation*D80 & & & & & $\begin{array}{c}-0.02 \\
()\end{array}$ & $\begin{array}{l}-0.31 \\
(* * *)\end{array}$ & $\begin{array}{c}0.03 \\
()\end{array}$ & $\begin{array}{c}-0.08 \\
()\end{array}$ \\
\hline Econ. freedom*D80 & & & & & $\begin{array}{c}0.08 \\
(* * *)\end{array}$ & $\begin{array}{c}0.12 \\
(* * *)\end{array}$ & $\begin{array}{c}0.09 \\
(* * *)\end{array}$ & $\begin{array}{c}0.09 \\
(* * *)\end{array}$ \\
\hline Adjusted $\mathrm{R}^{2}$ & 0.94 & 0.92 & 0.94 & 0.94 & 0.96 & 0.94 & 0.96 & 0.95 \\
\hline S.E. of regression & 0.91 & 1.04 & 0.89 & 0.92 & 0.78 & 0.92 & 0.75 & 0.79 \\
\hline F-statististic & $\begin{array}{c}438.72 \\
(* * *)\end{array}$ & $\begin{array}{c}317.85 \\
(* * *)\end{array}$ & $\begin{array}{c}446.19 \\
(* * *)\end{array}$ & $\begin{array}{l}416.4 \\
(* * *) \\
\end{array}$ & $\begin{array}{c}491.72 \\
(* * *)\end{array}$ & $\begin{array}{c}339.12 \\
(* * *)\end{array}$ & $\begin{array}{l}506.7 \\
(* * *)\end{array}$ & $\begin{array}{c}466.44 \\
(* * *)\end{array}$ \\
\hline
\end{tabular}

Note: Dependent variables are the credit rating levles. The symbols ${ }^{* * *},{ }^{* *}$ and ${ }^{*}$ denote statistical significance at the 1\%, 5\% and 10\% level, based on the White robust standard error estimator. All equations include fixed effects. 
higher ratings.

The results obtained for the alternative non-linear specification are, in terms of the direction of the reaction, largely in line with those from the baseline model. For instance, the signs related to public debt are negative, as expected. Still, the estimated parameter values are much lower, if we consider only those countries with public debt levels below $80 \%$ of GDP. However, if a country exceeds the public debt threshold of $80 \%$, rating agencies will penalize all further public debt increases more strongly. On the other hand, the surplus parameter, after controlling for non-linearity, becomes statistically insignificant for the majority of analyzed agencies. The estimated parameters related to the unemployment rate are very similar to those from the linear specification, where we have to note that rating agencies will penalize higher unemployment rates more strictly if the analyzed country exceeds the $80 \%$ public debt threshold. The results in Table 5 additionally suggest a statistically significant positive relationship between real economic activities (GDP growth) and credit rating, without any statistically significant difference with respect to the debt level. The signs and values of parameters related to interest payments are in line with those obtained in the baseline specification. Again, no significant non-linearity was found. A similar conclusion can be drawn about the inflation rate. Parameters connected with the index of economic freedom are also in line with those obtained from the baseline model, with a slightly stronger relationship for countries with public debt above $80 \%$ of GDP.

\subsection{Rating implied by fundamentals and rating over/under esti- mation}

Model In order to estimate the ratings implied by fundamentals we rounded the obtained regression fit (in-sample forecast $\hat{c}+\hat{\eta}_{i, t}+\hat{\beta}_{1}^{\prime} X_{i, t}+\hat{\beta}_{2}^{\prime} D_{80} X_{i, t}$ ) from the previous subsection to the nearest integer number. This indicator then represents the expected (predicted) rating based exclusively on the information available from macroeconomic fundamentals. In order to better understand to which extent the observed actions of rating agencies can really be reconstructed from the movements of macroeconomic fundamentals, we compared the earlier estimated implied ratings with the corresponding observed ratings.

Results Table 6 shows the results of the accuracy evaluation of the estimated models. This table presents the percentage of accurately predicted ratings (zero error) and the percentage of ratings that were predicted within at most one or two notches. The results shown suggest that the estimated systematic part is able to capture the dynamics of the true credit rating very well. Between $48 \%$ and $60 \%$ of ratings are accurately predicted. The non-linear 
Table 6: Precision of the estimated credit rating models

\begin{tabular}{lccccccccc}
\hline \hline & \multicolumn{4}{c}{ Baseline Model } & & \multicolumn{4}{c}{ Nonlinear Model } \\
\cline { 2 - 4 } \cline { 8 - 10 } & SP & Moody's & Fitch & Average & & SP & Moody's & Fitch & Average \\
\hline Correct prediction & 0.49 & 0.48 & 0.53 & 0.48 & & 0.55 & 0.59 & 0.60 & 0.60 \\
Within 1 notch & 0.86 & 0.85 & 0.89 & 0.88 & & 0.89 & 0.89 & 0.91 & 0.91 \\
Within 2 notches & 0.97 & 0.95 & 0.97 & 0.97 & & 0.97 & 0.96 & 0.98 & 0.97 \\
\hline
\end{tabular}

models for Fitch and for the average rating predicted the ratings with a high degree of accuracy within one notch (91\%), while the model for Moody's is slightly less precise (85\% for the linear and $89 \%$ for the non-linear specification). Models for all agencies are able to predict ratings within two notches with a very high degree of accuracy, exceeding $95 \%$. These results suggest that by using the standard set of macroeconomic and fiscal fundamentals one may very precisely replicate the ratings of European countries.

Ratings implied by fundamentals, together with actual ratings for all analyzed countries and each rating agency are shown in Figures 1 to 4 of the Appendix to this paper. These figures suggest that the majority of changes in credit ratings of EU countries are accompanied by changes in respective implicit ratings. For example, the majority of downgrades during the European sovereign debt crisis of 2011 - 2012 were predicted by the implied ratings estimated here. The only outlier is Spain, where a visible gap between observed and implied ratings opened during the mentioned crisis. Moreover, we can conclude that the majority of $A A A$ rated countries (level 17 at the numerical scale used here), well deserved to be in this category according to the underlying economic fundamentals. The only exception is UK whose rating, according to estimated specifications, should have been downgraded already in 2009 according to its economic fundamentals. The actual downgrades, however, occurred in 2013. These delayed decisions may point to rather cautious reactions of rating agencies which means that they neglect short-term cyclical fluctuations in underlying fundamentals and base their decisions on longer-term trends. A country recently showing slightly greater divergence of the rating implied by fundamentals from the actual rating is Hungary. Its rating has recently, depending on the agency, been underestimated by two to three categories. However, it would be wrong to fully interpret this difference between the true and the implied ratings as a rating underestimation, because a part of these differences could, for instance, be attributed to additional political and institutional factors which are not adequately included in our analysis. This argument can be confirmed by the rating downgrade statements of the rating agencies. For instance, in January 2012 when downgrading Hungary to junk Fitch stated the following: "Additional unorthodox policy measures have further undermined confidence in 
policy making." Similarly, S\&P stated the following in December 2011: "...the predictability and credibility of Hungary's policy framework continues to weaken. We believe this weakening is due, in part, to official actions that, in our opinion, raise questions about the independence of oversight institutions and complicate the operating environment for investors..."

At this point it is important to emphasis that our rating equations include only one regressor measuring institutional and political factors - the economic freedom index, while, on the other hand, seven economic and fiscal variables are included. We have, thus, estimated alternative specifications, extending the baseline specification with other institutional quality indicators (different components of the World Bank's Doing Business Indicator and the Corruption Perception Index). However, none of them proved to be statistically significant and the results in terms of implied ratings remained unaffected. In addition to these indicators, the Economic Policy Uncertainty Index becomes widely used in empirical research and one would expect that it may satifactionary capture a significant portion of political factors in our analysis, as for instance the aforementioned residual for Hungary during the last three years. However, this index is not available for smaller countries included in our sample. We have therefore estimated rating regressions for a narrow set of countries for which data on economic policy uncertainty was available (Germany, UK, France Italy and Spain). Again, we were not able to find any statistically significant relationship between credit ratings and these indicators. This is not surprising due to the fact that no persistent residuals for this subsample were found in our baseline rating regressions. In general, compared to the related research, our sample is rather homogeneous regarding political and institutional factors due to the fact that all countries are EU members. Moreover, we assume that most of the remaining persistent heterogeneity between countries related to these factors is captured by cross-country fixed effects. The only longer lasting residual is observed for Hungary and this can anecdotally be explained by political factors as already mentioned in the previous paragraph. On the other hand, for all other countries no persistent deviations of implied from actual ratings were found. In order to gain a deeper insight into the effect of political factors, one would have to analyze a sample with more cross-country variation. ${ }^{12}$ For the sample used in the present paper, indices based on news or online search engines may be more suitable in order to identify specific short-term differences in political uncertainty. Such indices are, however, not readily available for a wide set of countries. The availability of a database containing such indicators for all EU countries would clearly be useful for examining the importance of rating agencies and the influence of political instabilities on

\footnotetext{
${ }^{12}$ For instance, Butler and Fauver (2006) provide a detailed analysis about the effect of political indicators on Institutional Investor Ratings by using cross-sectional data on a heterogeneous set of 96 countries including both emerging and developed economies.
} 
credit ratings. However, we argue that building such a database and analyzing the impact of political factors on credit ratings can be considered a research topic on its own and it would go beyond the scope of the present paper. We are, thus, not addressing it in this paper and leave it for future research.

\section{Decomposition of CDS spreads}

In this section we analyze whether rating agencies reveal important new information to financial markets that has not yet been absorbed in the borrowing cost of a country. For this purpose we use ratings implied by fundamentals and the indicators of credit rating overestimation and estimate their impact on CDS spreads. The mentioned overestimation indicator, that is, the unexplained component of the credit rating (the residual in equation 2) approximates the discretionary actions of rating agencies. It contains specific information on the rating of a country which does not follow the dynamics of economic fundamentals that are included in this analysis - it is independent (orthogonal) from the credit rating implied by fundamentals. This indicator of discretionary actions of rating agencies approximates the market power of rating agencies, i.e. the influence of their autonomous actions on financial markets. However, as already explained in the previous section, this component is not a perfect measure of rating overestimation and this has to be kept on mind when interpreting the results.

Model For the purpose of this exercise, it is necessary to differentiate the degree to which credit ratings and the borrowing cost are correlated due to macroeconomic fundamentals that simultaneously determine both the credit rating and the borrowing cost, and the degree to which the credit rating by itself is informative for financial markets, independently from the information obtained from macro fundamentals. In order to disentangle the influence of credit ratings on the borrowing cost via the two channels we first estimated a linear panel data model in which CDS spreads of EU countries are regressed on the rating implied by fundamentals and the rating overestimation indicators, while controlling for external factors. More precisely, the following equation is estimated:

$$
C D S_{i, t}=\alpha_{0}+\eta_{i, t}+\alpha_{1} \hat{R}_{i, t}+\alpha_{2} \widehat{\varepsilon}_{i, t}+\alpha_{3} V X_{i, t}+\epsilon_{i, t}
$$

where $\alpha_{0}, \alpha_{1}, \alpha_{2}$ and $\alpha_{3}$ represent the unknown parameters, $\eta_{i, t}$ fixed effects, $\hat{R}_{i, t}=\widehat{c}+\widehat{\eta}_{i, t}+$ $\widehat{\beta}_{1}^{\prime} X_{i, t}+\hat{\beta}_{2}^{\prime} D_{80} X_{i, t}$ the rating implied by fundamentals, $\widehat{\varepsilon}_{i, t}$ the residual from the previous chapter, i.e. the rating overestimation indicator, $V X_{i, t}$ is the global risk aversion, while $\epsilon_{i, t}$ is 
a normally distributed error with zero expectation. ${ }^{13}$ The contribution of variable $\hat{R}_{i, t}$ can, thus, be interpreted as the effect that the predictable component of the credit rating has on CDS spreads. In other words, it contains all the information that enters the reaction function of both parties; investors in government bonds as well as rating agencies. Consequently, a change in credit rating due to $\hat{R}_{i, t}$ represents no surprise for the financial market. On the other hand, $\widehat{\varepsilon}_{i, t}$ represents new information to investors.

It is necessary to point to the fact that two regressors from equation 3 (rating overestimation indicator, $\widehat{\varepsilon}_{i, t}$, and rating implied by fundamentals, $\hat{R}_{i, t}$,) are not observed variables but estimates of unobserved variables - i.e. generated regressors. For such regressors usual OLS estimates of standard errors are generally biased. These estimates do not take into account the uncertainty arising from the estimation of these unobserved regressors. Consequently, the respective standard errors will be underestimated (Pagan, 1984, and Murphy and Topel, 1985). In this paper we addressed the problem of generated regressors by using the two-step bootstrap method so that we choose random samples from the estimated residuals for both steps, i.e. for both regressions used (equation 2 and 3). The estimated bootstrap standard errors, based on 30000 random draws, are shown in Table 7.

Results The estimated parameters of equation 3 for all three agencies and the average rating are given in Table 7 . The obtained results suggest that all variables used are statistically significant in explaining the dynamics of CDS spreads. The signs of all three parameters are also in line with expectations. Thus, the parameters related to risk aversion are positive, which means that higher global risk aversion will materialize in higher spreads. Further, the fundamental rating component is negatively correlated to the borrowing cost. Finally, the rating overestimation indicator is, on average, related to lower spreads.

\subsection{Discussion of the economic significance of rating agencies}

The interpretation of the results presented above warrants caution. Namely, the statistical significance of the respective parameter could point to a conclusion that discretionary credit rating actions really can affect the borrowing cost of European countries. However, the mentioned statistical significance is not sufficient to conclude about the relative importance of

\footnotetext{
${ }^{13}$ We have also tried specification expanded by the common factor of European CDS spreads as an additional control variable which approximates the spillover index. However, the problem is that the mentioned variable also contains information on the common fundamentals of analyzed countries leading to a significant correlation between the mentioned spillover index and the rating implied by fundamentals used here. It is also noteworthy that the objective of this paper is to examine the relative importance of the discretionary actions of rating agencies and fundamentals, while the impact of spillover and contagion on the borrowing cost is analyzed in more detail in Kunovac (2013). Therefore, in this paper we will use the volatility index as the only control variable.
} 
Table 7: The effect of the rating overestimation indicator, rating implied by fundamentals and risk aversion index on CDS spreads

\begin{tabular}{lcccc}
\hline \hline & S\&P & Moody's & Fitch & Average \\
\hline Intercept & 757.79 & 494.19 & 789.79 & 665.23 \\
& $(* *)$ & $(* *)$ & $(* * *)$ & $(* *)$ \\
Fundamentals & -52.73 & -36.09 & -52.38 & -46.20 \\
& $(* * *)$ & $(* * *)$ & $(* * *)$ & $(* * *)$ \\
Overestimation indicator & -27.01 & -34.90 & -33.28 & -34.69 \\
& $(* * *)$ & $(* * *)$ & $(* * *)$ & $(* * *)$ \\
Risk aversion & 7.02 & 7.14 & 6.87 & 7.01 \\
& $(* * *)$ & $(* * *)$ & $(* * *)$ & $(* * *)$ \\
\hline Adjusted R ${ }^{2}$ & 0.58 & 0.57 & 0.59 & 0.59 \\
S.E. of regression & 99.45 & 100.87 & 98.24 & 99.07 \\
\hline Note: Depencis
\end{tabular}

Note: Dependent variables are quarterly averages of CDS spreads. The symbols $* * *, * *$ and $*$ denote statistical significance at the $1 \%, 5 \%$ and $10 \%$ level, based on two-step bootstrap standard errors.

rating agencies for CDS spreads in comparison to the relative importance of economic fundamentals and other factors. The relative importance of individual variables in the model may be analyzed in the context of the importance of the variable for: 1) describing the variability of spreads and 2) the importance of the variable for describing the level of spreads. For the purpose of examining the relative importance of a regressor for describing the variability of the dependent variable in a regression, it is necessary to analyze the marginal effect of each of the used regressors on the $R^{2}$ statistic. In order to carry out the said decomposition, we apply the method described in Lindeman, Merenda and Gold (1980), which was previously used to decompose European spreads in Kunovac (2013). For each possible variable ranking and each variable in the model this method calculates the marginal influence its inclusion has on the $R^{2}$ statistic. The final estimate of the contribution of the variance of a given variable is calculated as the average of these marginal contributions over all possible orders of the variables in the model.

Table 8 shows the results of the mentioned variance decomposition of CDS spreads to relative contributions of rating overestimation indicator, rating implied by fundamentals and risk aversion for each rating agency and average rating. The figures suggest that the greatest contribution to the variance of CDS spreads of European countries result from risk aversion (between 59\% and 66\%), which is in line with results in Kunovac (2013). The contribution of ratings implied by fundamentals is slightly lower (between $27 \%$ and $36 \%$ ). On the other hand, the contribution of the overestimation indicator is the lowest in all four equations 
Table 8: CDS spreads variance decomposition

\begin{tabular}{lcccc}
\hline \hline & S\&P & Moody's & Fitch & Average \\
\hline Fundamentals & 0.36 & 0.27 & 0.36 & 0.33 \\
Overestimation indicator & 0.04 & 0.07 & 0.05 & 0.06 \\
Risk aversion & 0.60 & 0.66 & 0.59 & 0.61 \\
\hline Note: The values are representing contributions of the respective variable to \\
the $\mathrm{R}^{2}$ statistics of equation 3.
\end{tabular}

(between $4 \%$ and $7 \%$ ). These results point to the conclusion that rating agencies have a very limited influence on CDS spreads compared to the influence of fundamentals and external factors. The preliminary results obtained in the event study analysis in section 2 are hereby additionally justified.

As already listed above, the second exercise used for accessing the relative importance of discretionary rating actions is the decomposition of the CDS spread level. The contributions are obtained by simply multiplying each of the regressors in equation 2 by the corresponding parameter estimate.

Figures 5 to 8 of the Appendix show the relative contribution of the rating overestimation indicators together with the CDS spreads for analyzed European countries. ${ }^{14}$ The positive (negative) values of the contribution by this indicator imply underestimated (overestimated) credit rating. This means that for such a country the CDS is higher (lower) than implied by the underlying fundamentals and risk aversion indicator. More precisely, assuming everything else equal, the markets are demanding higher (lower) spreads for the analyzed country due to its overestimated (underestimated) rating.

The mentioned figures suggest that the contribution of the overestimation indicator represents only a negligible part of the spread level during the analyzed period. It contributes less than 60 basis points in absolute terms to spread levels for almost all countries, while the average absolute contribution totals merely 20 basis points. The limited relevance of rating agency's discretionary actions is clearly illustrated by comparing the mentioned average 20 basis points with observed spread levels. For instance, during the great recession of 2008 to 2009 and the European sovereign debt crisis, CDS spreads for most European countries quickly exceeded 400 basis points, while for countries that were hardly hit by the crises they exceeded levels of as much as 800 basis points. During this time, global risk aversion was the most important driving force of CDS spreads (not shown in graphs) whose influence was

\footnotetext{
${ }^{14}$ In order to save space, the graphs are depicting the contribution of the overestimation indicator only, while the contributions of the other two regressors are available on request.
} 
several times stronger than the influence of discretionary actions of rating agencies. It is important to note that the contribution of agencies discretionary actions were by no means the main driving factor of CDS spreads during the mentioned sovereign debt crises. With the exception of Spain, all other countries had negative, zero or at most negligible positive contributions of discretionary rating actions as shown in Figures 5 to 8. We can therefore conclude that rating agencies softened, or at least didn't intensify, the strong increase in CDS spreads during the sovereign debt crises. This is in contrast to the findings in Gartner et al. (2011) and to the views of many policymakers in Europe. The strongest negative contribution of discretional actions of rating agencies can be found for UK's CDS spreads. They were around 50 basis points below its fundamental level during the period from 2011 to 2012. For most other countries, this contribution was bellow 50 basis points in absolute terms, which is, as already mentioned, rather insignificant in comparison to the contribution of the other two factors. Regarding the more recent period, only Hungary has been more severely affected by discretionary credit ratings actions. Depending on the rating agency, its CDS spread was around 60-70 basis points above the level implied by the underlying fundamentals and global risk aversion. However, as already explained in the previous section, this could be related to some political factors that are not adequately addressed in this paper.

All results shown indicate that fundamentals, along with the global risk aversion, are the most important determinants of CDS spreads of European countries. On the other hand the discretional credit rating actions explain only a negligible part of the variation in CDS spreads. We can therefore conclude that the credit rating itself does not contain much valuable information in addition to that already contained in the economic fundamentals.

\section{$5 \quad$ Market implied rating}

Rating agencies mostly refrain from reacting to economic fluctuations they assess to be shortterm only. On the other hand, market participants tend to react immediately to news about the fundamentals for which they assess that might affect the creditworthiness of a country as a debt issuer. In this regard, markets can informally assign ratings to individual countries (or companies) - market implied ratings - that need not always be equivalent to the actual credit rating assigned by rating agencies. More precisely, countries with higher credit ratings need not always enjoy lower cost of borrowing than countries with lower credit ratings. Markets can, for instance, downgrade a debt issuer from the investment into the junk category much before rating agencies decide to do so. A comparison of actual ratings assigned by rating agencies and informal, market implied ratings may provide further insight into the causal relationship between rating agencies and financial markets. 
Model For the purpose of determining boundaries (thresholds) between informal, market implied rating categories, we applied a method used in Berger et al (2002), and Kou and Varotto (2005) which, to our knowledge, has not been used for sovereign spreads yet. The mentioned method estimates borders between rating categories by minimizing a simple penalty function. As stressed earlier, the ranking of a set of countries by their credit rating is not necessary in line with their ranking by CDS spreads. The used method thus searches for the optimal threshold between rating categories so as to penalize this inconsistency. In particular, the ratings of a group of countries are first divided into $k$ categories. Then, for each period $t$ and each rating category a penalty function is defined, which depends on the assumed threshold between the respective and the bordering category. The objective of the algorithm is to find the value of the threshold which will minimize the penalty function shown below, that is, to minimize the inconsistency between rating rankings and spreads:

$$
P(g)=\frac{1}{m} \sum_{i=1}^{m} \max \left(S_{i, R_{1}}-g, 0\right)+\frac{1}{n} \sum_{j=1}^{n} \max \left(g-S_{j, R_{2}}, 0\right)
$$

where $g$ represents the assumed threshold, $S_{i, R_{1}}$ the spread of $i$-th country with rating $R_{1}$, $S_{j, R_{2}}$ represents the spread of the $j$-th country with rating $R_{2}$ (i.e. one category below $R_{1}$ ), $m$ is the number of countries which had rating $R_{1}$ in the observed period, while $n$ is the number of countries that had rating $R_{2}$ in the observed period. The equation clearly shows that the value of the function will increase due to an increase in the first term, when the selected $g$ is bellow the optimum level, while the second term increases, when the selected $g$ is above the optimum level.

Data The rating scale is divided into four categories. The first category comprises only countries with the highest possible rating $(A A A)$. Next to follow is the category that comprises countries which at a given moment had another rating, but still one within the investment category. The third category comprises countries with ratings in the speculative category $B B+$ and $B$-, while the fourth category includes all other speculative ratings below $B-.{ }^{15}$ In order to carry out such an analysis it is necessary to have at least one country in each of the rating category at all times. For this reason, the group of countries was expanded by twenty non-EU countries with available comparable data on CDS spreads and credit ratings, which did not default over the last twenty years. ${ }^{16}$ This analysis is carried out on monthly

\footnotetext{
${ }^{15}$ Other specifications of rating categories have been estimated as well, and the estimated boundaries between the speculative and investment categories remained almost unchanged in relation to the division suggested here.

${ }^{16}$ In addition to EU member states, the following countries were included: Australia, Brazil, Chile, Canada, Indonesia, Israel, Japan, South Korea, Kazakhstan, Mexico, Malaysia, Norway, Panama, Peru, the Philip-
} 
data for the period $2008 \mathrm{~m} 1$ to $2015 \mathrm{~m} 9$ which includes 4464 observations. Only S\&P provides data on credit ratings for all countries listed for a sufficiently long period. Therefore, the analysis was conducted only for this agency. However, the results obtained in earlier sections of this paper indicate similar behavior of all three rating agencies. Hence, the results obtained here for $\mathrm{S} \& \mathrm{P}$ can be considered sufficiently representative for our analysis.

A strong common component in CDS spreads may contaminate the results of the present analysis due to occasional strong spread jumps caused by common global shocks. For this reason, we extract these common factors from CDS spreads in such a way that the respective spread for each country was regressed on the estimated principal component from spreads of all countries. The resulting residuals (together with the respective intercept) obtained by this regression are used for further analysis and they represent CDS spreads cleaned of common factors. Therefore, this chapter will seek to find the representative boundary between CDS spread residuals constructed in this way. In order for the obtained result to be as clear as possible, the threshold between the speculative and the investment category will be shown, which is according to the results obtained in chapter 2 the only threshold that receives special attention by market participants.

Results Figure 9 in the Appendix, shows the difference between CDS residuals and the estimated threshold between the junk and the investment category. Positive numbers indicate countries which are placed in the junk category according to the financial market. In order for these results to be compared to actual ratings, we added thick lines to the Figure which indicate periods during which respective countries were actually placed in the junk category, according to $\mathrm{S} \& \mathrm{P}$.

These results suggest that financial markets have almost always anticipated downgrades to the speculative category. ${ }^{17}$ Thus, CDS residuals crossed over to the positive territory prior to the actual downgrade for all five countries for which the actual rating was downgraded from investment to speculative category. For instance for Croatia, markets had anticipated S\&P's decision almost two years before the actual downgrade to the junk category. The results for Hungary and Portugal are in line with the ones for Croatia for both the entry into junk category and the assessment of the recent period. If we compare the result for Hungary with the results related to its underestimated rating from sections 3, it becomes clear that investors in the bond market have the same perception of Hungary's risk as rating agencies. This points to the fact that both; markets and rating agencies value political factors, which are however not fully covered by the analysis in section 3. Moreover, the results suggest that

pines, Qatar, Russia, Thailand, Turkey and South African Republic.

${ }^{17}$ Similar results about the lagged reaction of credit rating agencies was found in Reinhart (2002). 
markets anticipated downgrades to junk also for the remaining two countries: Romania and Latvia. These two countries are the only ones that returned from junk into the investment category in the analyzed sample. Figure 9 shows that the financial markets anticipated Latvia's upgrade about 3 months in advance, while the return of Romania to the investment category was rather surprising.

It should also be noted that due to high spread variability it often comes to false signals of downgrades to junk category. Thus, even for countries with highest credit ratings, potential downgrades to the speculative category are observed within a very short period of only several months. These findings point to the fact that rating agencies are cautious when revising ratings which means that they largely neglect short-term cyclical fluctuations in economic fundamentals and base their decisions on long-term trends in fundamentals. On the other hand, market participants tend to react immediately to changes in the underlying economic fundamentals and therefore the used method often shows such false signals in the short run. However, as already mentioned before, any longer deviation of market implied ratings from actual ratings is eventually followed by an actual rating change.

The results presented in this chapter confirm the thesis that rating agencies do not have a significant impact on the borrowing cost and that investors in the financial markets anticipate future rating changes.

\section{Conclusion}

In this paper we examine the relevance of changes in sovereign credit rating for the borrowing cost of EU countries. We can conclude that the economic importance of autonomous credit rating announcements has been rather limited for the countries and time period under analysis. Although the average reaction of spreads to rating announcements proved to be statistically significant, its economic relevance seems to be rather small. Only downgrades from the investment into the junk category can be considered valuable information for the financial market. These findings are in line with other related research, as for instance Afonso et al (2012) and Jaramillo and Tejada (2011), while some other papers found stronger reactions to rating changes (Cantor and Packer, 1996 or Aizeman et al, 2013 among others). Moreover, it seems that rating agencies do not provide financial market participants with any significant information in addition to that already contained in macroeconomic fundamentals. Contrary to Gärtner et al (2011), our results suggest that rating agencies can by no means be blamed for amplifying the sovereign debt crisis. The main driver of soaring spreads during the mentioned period was the overall risk aversion and significant worsening of fiscal fundamentals in most EU countries. Moreover, our analysis suggests that rating 
agencies react with some delay to changes in underlying fundamentals, while markets tend to absorb such changes immediately. Therefore, given the sentiment in financial markets, government's borrowing cost can only be reduced by improving macroeconomic and fiscal fundamentals. Any increase in the credit rating may then follow only as a consequence of these improvements.

According to our results, one may conclude that rating agencies should not be overly important for public discussions and, hence, that policymakers are indeed overrating the importance of rating agencies. However, this is not necessarily true. It seems crucial to distinguish between two important cases in that regard - policymakers may be aware of our results or, alternatively, unaware of them. We argue that our results may be relevant in both cases. First, if policymakers are aware of the results, they may be willing to use credit ratings as a communication device in order to justify implementation of structural reforms and spending cuts. Due to the fact that it is generally difficult to implement structural reforms, governments may want to point to rating agencies that are enforcing such reforms. However, even if this explanation holds true, our results suggest that using the borrowing cost of a country may be more suitable for the mentioned purpose when communicating reforms. Indeed, if market participants already absorbed all available information into bond yields there may be no need to include rating agencies into communication strategy. The general public may probably better understand the importance of reforms through interest rates the government is paying on its debt than introducing the role of rating agencies.

Second, our results can be of interest even if policymakers are unaware of them. In that case we argue that our results may inform the public discussion about the importance of sovereign credit ratings. 


\section{References}

[1] Afonso, A. 2003: Understanding the determinants of sovereign debt ratings: Evidence for the two leading agencies. Journal of Economics and Finance, Springer, vol. 27(1), pages 56-74, March.

[2] Afonso, A., Gomes, P. and Rother, P. 2009: Ordered response models for sovereign debt ratings. Applied Economics Letters, Taylor \& Francis Journals, vol. 16(8), pages 769-773.

[3] Afonso, A., Furceri, D. and Gomes, P. 2012: Sovereign credit ratings and financial markets linkages: Application to European data. Journal of International Money and Finance, Elsevier, vol. 31(3), pages 606-638.

[4] Afonso, A., Arghyrou, M. G. and Kontonikas, A. 2015: The determinants of sovereign bond yield spreads in the EMU. Working Paper Series 1781, European Central Bank.

[5] Aizenman, J., Binic, M. and Hutchison, M. 2013: Credit Ratings and the Pricing of Sovereign Debt during the Euro Crisis. NBER Working Papers 19125, National Bureau of Economic Research, Inc.

[6] Berger, L., Goldberg, L. and Cheyette, O. 2002: Market Implied Ratings. The Barra Credit Series Research Insights.

[7] Bissoondoyal-Bheenick, E. 2004: An analysis of the determinants of sovereign ratings. Global Finance Journal, Elsevier, vol. 15, pages 251 - 280.

[8] Butler, A., W., Fauver, L. 2006: Institutional Enviroment and Sovereign Credit Ratings. Financial Management Association, vol. 35(3), Autumn. 15, pages $53-79$.

[9] Cantor, R. and Packer, F. 1996: Determinants and impact of sovereign credit ratings. Economic Policy Review, Federal Reserve Bank of New York, issue Oct, pages 37-53.

[10] CNB 2012: The impact of changes in countries credit ratings on their borrowing costs. Croatian National Bank Bulletin 182, Box 5, June 2012.

[11] Dell'Ariccia, G., Schnabel, I., and Zettelmeyer, J. 2006: How Do Official Bailouts Affect the Risk of Investing in Emerging Markets? Journal of Money, Credit and Banking, Blackwell Publishing, vol. 38(7), pages 1689-1714, October.

[12] De Wit, J. 2006: Exploring the CDS-Bond Basis. Working Paper Research 104, National Bank of Belgium 
[13] Cavallo, E., Powell, A., and Rigobon, R. 2008: Do Credit Rating Agencies Add Value? Evidence from the Sovereign Rating Business. Research Department Publications 4601, Inter-American Development Bank, Research Department.

[14] Eichengreen, B and Mody, A 1998: What Explains Changing Spreads on EmergingMarket Debt: Fundamentals or Market Sentiment?. NBER Working Papers 6408, National Bureau of Economic Research, Inc.

[15] Ferri, G., Liu, L.-G., Stiglitz, J. E. 1999: The Procyclical Role of Rating Agencies: Evidence from the East Asian Crisis. Economic Notes, Banca Monte dei Paschi di Siena SpA, vol. 28(3), pages 335-355, November.

[16] Gärtner, M., Griesbach, B. and Jung, F. 2011: PIGS or Lambs? The European Sovereign Debt Crisis and the Role of Rating Agencies. International Advances in Economic Research, International Atlantic Economic Society, vol. 17(3), pages 288-299, August.

[17] IMF 2010: Sovereigns, Funding and Systemic Liquidity. Global Financial Stability Report, International Monetary Fund, Washington DC, October, 2010.

[18] Jaramillo, L., Tejada, C., M. 2011: Sovereign Credit Ratings and Spreads in Emerging Markets: Does Investment Grade Matter? IMF Working Paper Series 11/44. International Monetary Fund

[19] Kaminsky G, Schmukler S. 2002: Emerging Market Instability: Do Sovereign Ratings Affect Country Risk and Stock Returns? The World Bank Economic Review 16(2): $171-195$.

[20] Kou, J. and Varotto, S. 2005: Predicting Agency Rating Migrations with Spread Implied Ratings. ICMA Centre Discussion Papers in Finance icma-dp 2005-06, Henley Business School, Reading University.

[21] Kunovac, D. 2012: Sovereign credit ratings of European countries - main determinants and their impact on borrowing costs. Croatian National Bank, mimeo.

[22] Kunovac, D. 2013: The Borrowing Costs of Selected Countries of the European Union the Role of the Spillover of External Shocks. CNB Working papers, W - 38, May 2013.

[23] Lindeman R. H., Merenda, P. F. and Gold, R. Z. 1980: Introduction to Bivariate and Multivariate Analysis. Scott, Foresman, Glenview, Il. 
[24] Murphy, K., M. and Topel, R., H, 1985: Estimation and Inference in Two-Step Econometric Models. Journal of Business \& Economic Statistics, American Statistical Association, vol. 3(4), pages 370-79, October.

[25] Özmen, E., and Yaşar, Ö. D. 2015: Emerging Markets Sovereign Bond Spreads, Credit Ratings and Global Financial Crisis. ERC Working Papers 1510, ERC - Economic Research Center, Middle East Technical University, revised Nov 2015.

[26] Pagan, A. 1984: Econometric Issues in the Analysis of Regressions with Generated Regressors. International Economic Review, vol. 25(1), pages 221-47, February.

[27] Reinhart, C., M. 2002: Default, Currency Crises and Sovereign Credit Ratings. NBER Working Paper 8738

[28] Rowland, P. and Torres, J. L. 2013: Determinants of Spread and Creditworthiness for Emerging Market Sovereign Debt: A Panel Data Study. Borradores de Economia 295, Banco de la Republica de Colombia.

[29] Standard \& Poor's 2014: Sovereign Rating Methodology. S \& P Rating services, December 2014. [online] at https://www.standardandpoors.com/en_AP/web/guest/article//view/type/HTML/ id/1557417 
A Appendix 
Table 9: Determinants of sovereign credit ratings for different alternative specifications

\begin{tabular}{|c|c|c|c|c|c|c|c|}
\hline & $\mathrm{I}$ & II & III & IV & $\mathrm{V}$ & VI & VII \\
\hline Intercept & $\begin{array}{l}-6.31 \\
(* * *)\end{array}$ & $\begin{array}{l}10.71 \\
(* * *)\end{array}$ & $\begin{array}{c}2.62 \\
(* * *)\end{array}$ & $\begin{array}{c}8.54 \\
(* * *)\end{array}$ & $\begin{array}{c}-1.06 \\
(* *)\end{array}$ & $\begin{array}{l}3.87 \\
(* *)\end{array}$ & $\begin{array}{l}12.12 \\
(* * *)\end{array}$ \\
\hline Gov. debt & $\begin{array}{c}0.10 \\
(* * *)\end{array}$ & $\begin{array}{c}0.00 \\
(* * *)\end{array}$ & $\begin{array}{c}0.01 \\
(* * *)\end{array}$ & $\begin{array}{l}-0.04 \\
(* * *)\end{array}$ & $\begin{array}{c}0.00 \\
(* * *)\end{array}$ & $\begin{array}{l}-0.03 \\
(* * *)\end{array}$ & $\begin{array}{l}-0.01 \\
(* * *)\end{array}$ \\
\hline Budget balance & $\begin{array}{c}0.11 \\
(* * *)\end{array}$ & $\begin{array}{c}0.01 \\
()\end{array}$ & $\begin{array}{l}0.03 \\
(* *)\end{array}$ & $\begin{array}{c}-0.01 \\
()\end{array}$ & $\begin{array}{c}-0.01 \\
()\end{array}$ & $\begin{array}{c}-0.04 \\
(*)\end{array}$ & $\begin{array}{c}0.01 \\
()\end{array}$ \\
\hline Unemployment & $\begin{array}{l}-0.33 \\
(* * *)\end{array}$ & $\begin{array}{l}-0.16 \\
(* * *)\end{array}$ & $\begin{array}{l}-0.06 \\
(* * *)\end{array}$ & $\begin{array}{l}-0.14 \\
(* * *)\end{array}$ & $\begin{array}{l}-0.09 \\
(* * *)\end{array}$ & $\begin{array}{l}-0.15 \\
(* * *)\end{array}$ & $\begin{array}{l}-0.12 \\
(* * *)\end{array}$ \\
\hline GDP growth & $\begin{array}{c}-0.01 \\
()\end{array}$ & $\begin{array}{c}0.02 \\
()\end{array}$ & $\begin{array}{c}0.04 \\
()\end{array}$ & $\begin{array}{c}0.04 \\
(* * *)\end{array}$ & $\begin{array}{c}0.05 \\
(* * *)\end{array}$ & $\begin{array}{c}0.05 \\
(* * *)\end{array}$ & $\begin{array}{l}0.02 \\
(* *)\end{array}$ \\
\hline Interest payments & $\begin{array}{l}-1.23 \\
(* * *)\end{array}$ & $\begin{array}{l}-0.89 \\
(* * *)\end{array}$ & $\begin{array}{l}-0.58 \\
(* * *)\end{array}$ & $\begin{array}{c}-0.37 \\
(* *)\end{array}$ & $\begin{array}{l}-0.74 \\
(* * *)\end{array}$ & $\begin{array}{l}-0.65 \\
(* * *)\end{array}$ & $\begin{array}{l}-0.99 \\
(* * *)\end{array}$ \\
\hline Inflation & $\begin{array}{c}-0.1 \\
(*)\end{array}$ & $\begin{array}{c}-0.05 \\
()\end{array}$ & $\begin{array}{c}0.06 \\
(* * *)\end{array}$ & $\begin{array}{c}-0.03 \\
()\end{array}$ & $\begin{array}{l}0.06 \\
(* *)\end{array}$ & $\begin{array}{c}0.02 \\
()\end{array}$ & $\begin{array}{c}-0.04 \\
(*)\end{array}$ \\
\hline Econ freedom & $\begin{array}{c}0.3 \\
(* * *)\end{array}$ & $\begin{array}{c}0.09 \\
(* * *)\end{array}$ & $\begin{array}{c}0.05 \\
(* * *)\end{array}$ & $\begin{array}{c}0.01 \\
()\end{array}$ & $\begin{array}{l}0.01 \\
(* *)\end{array}$ & $\begin{array}{c}0.03 \\
(* * *)\end{array}$ & $\begin{array}{c}0.08 \\
(* * *)\end{array}$ \\
\hline Gov. debt*D80 & $\begin{array}{l}-0.07 \\
(* * *)\end{array}$ & $\begin{array}{l}-0.08 \\
(* * *)\end{array}$ & $\begin{array}{l}-0.05 \\
(* * *)\end{array}$ & $\begin{array}{l}-0.07 \\
(* * *)\end{array}$ & $\begin{array}{l}-0.04 \\
(* * *)\end{array}$ & $\begin{array}{l}-0.07 \\
(* * *)\end{array}$ & $\begin{array}{l}-0.08 \\
(* * *)\end{array}$ \\
\hline Budget balance*D80 & $\begin{array}{c}-0.06 \\
()\end{array}$ & $\begin{array}{c}-0.06 \\
(*)\end{array}$ & $\begin{array}{l}-0.17 \\
(* * *)\end{array}$ & $\begin{array}{c}-0.07 \\
(* *)\end{array}$ & $\begin{array}{c}-0.03 \\
()\end{array}$ & $\begin{array}{c}-0.01 \\
()\end{array}$ & $\begin{array}{c}-0.07 \\
(* *)\end{array}$ \\
\hline Unemployment*D80 & $\begin{array}{l}-0.15 \\
(* * *)\end{array}$ & $\begin{array}{l}-0.13 \\
(* * *)\end{array}$ & $\begin{array}{l}-0.26 \\
(* * *)\end{array}$ & $\begin{array}{l}-0.14 \\
(* * *)\end{array}$ & $\begin{array}{l}-0.27 \\
(* * *)\end{array}$ & $\begin{array}{l}-0.14 \\
(* * *)\end{array}$ & $\begin{array}{l}-0.13 \\
(* * *)\end{array}$ \\
\hline GDP growth*D80 & $\begin{array}{c}0.01 \\
()\end{array}$ & $\begin{array}{c}0.04 \\
()\end{array}$ & $\begin{array}{c}0.04 \\
()\end{array}$ & $\begin{array}{c}0.05 \\
()\end{array}$ & $\begin{array}{c}0.01 \\
()\end{array}$ & $\begin{array}{c}0.02 \\
()\end{array}$ & $\begin{array}{c}0.06 \\
(*)\end{array}$ \\
\hline Interest payments*D80 & $\begin{array}{c}0.28 \\
()\end{array}$ & $\begin{array}{c}0.11 \\
()\end{array}$ & $\begin{array}{c}0.62 \\
(*)\end{array}$ & $\begin{array}{c}0.12 \\
()\end{array}$ & $\begin{array}{c}0.18 \\
()\end{array}$ & $\begin{array}{l}0.15 \\
(* *)\end{array}$ & $\begin{array}{c}0.17 \\
()\end{array}$ \\
\hline Inflation*D80 & $\begin{array}{l}0.24 \\
(* *)\end{array}$ & $\begin{array}{c}-0.04 \\
()\end{array}$ & $\begin{array}{c}-0.08 \\
()\end{array}$ & $\begin{array}{c}-0.14 \\
(*)\end{array}$ & $\begin{array}{c}-0.06 \\
()\end{array}$ & $\begin{array}{c}-0.17 \\
(* *)\end{array}$ & $\begin{array}{c}-0.08 \\
()\end{array}$ \\
\hline Econ freedom*D80 & $\begin{array}{c}0.05 \\
(* * *)\end{array}$ & $\begin{array}{c}0.10 \\
(* * *)\end{array}$ & $\begin{array}{c}0.05 \\
(* * *)\end{array}$ & $\begin{array}{c}0.09 \\
(* * *)\end{array}$ & $\begin{array}{c}0.08 \\
(* * *)\end{array}$ & $\begin{array}{c}0.1 \\
(* * *)\end{array}$ & $\begin{array}{c}0.09 \\
(* * *)\end{array}$ \\
\hline $\mathrm{GDP} / \mathrm{pc}$ & & & $\begin{array}{c}1.64 \\
(* * *)\end{array}$ & $\begin{array}{c}1.74 \\
(* * *)\end{array}$ & $\begin{array}{c}5.03 \\
(* * *)\end{array}$ & $\begin{array}{c}4.83 \\
(* * *)\end{array}$ & \\
\hline $\mathrm{GDP} / \mathrm{pc}^{2}$ & & & & & $\begin{array}{l}-0.33 \\
(* * *)\end{array}$ & $\begin{array}{l}-0.3 \\
(* * *)\end{array}$ & \\
\hline Effects & Pooled & Random & Pooled & Random & Pooled & Random & Fixed \\
\hline Adjusted $\mathrm{R}^{2}$ & 0.83 & 0.67 & 0.92 & 0.72 & 0.96 & 0.74 & 0.98 \\
\hline S.E. of regression & 1.98 & 0.87 & 1.31 & 0.83 & 1.15 & 0.84 & 0.71 \\
\hline F-statistic & $\begin{array}{c}273 \\
(* * *)\end{array}$ & $\begin{array}{c}119.91 \\
(* * *)\end{array}$ & $\begin{array}{c}661.12 \\
(* * *)\end{array}$ & $\begin{array}{c}136.01 \\
(* * *)\end{array}$ & $\begin{array}{c}1306.14 \\
(* * *)\end{array}$ & $\begin{array}{c}143.51 \\
(* * *)\end{array}$ & $\begin{array}{c}1258.83 \\
(* * *)\end{array}$ \\
\hline
\end{tabular}


Figure 1: Rating implied by fundamentals and observed rating for S\&P
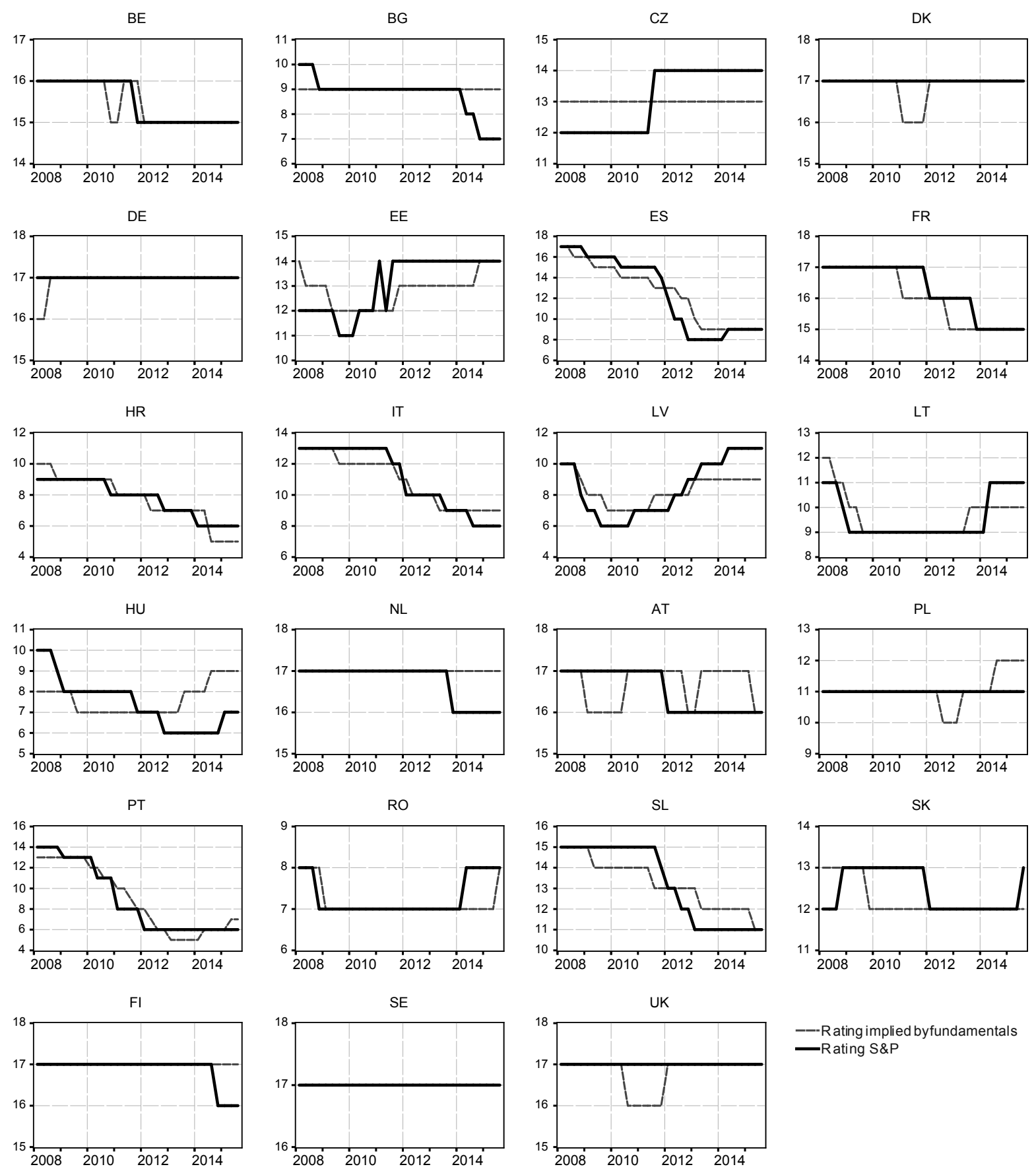

---Rating implied byfundamentals -Rating S\&P 
Figure 2: Rating implied by fundamentals and observed rating for Moody's
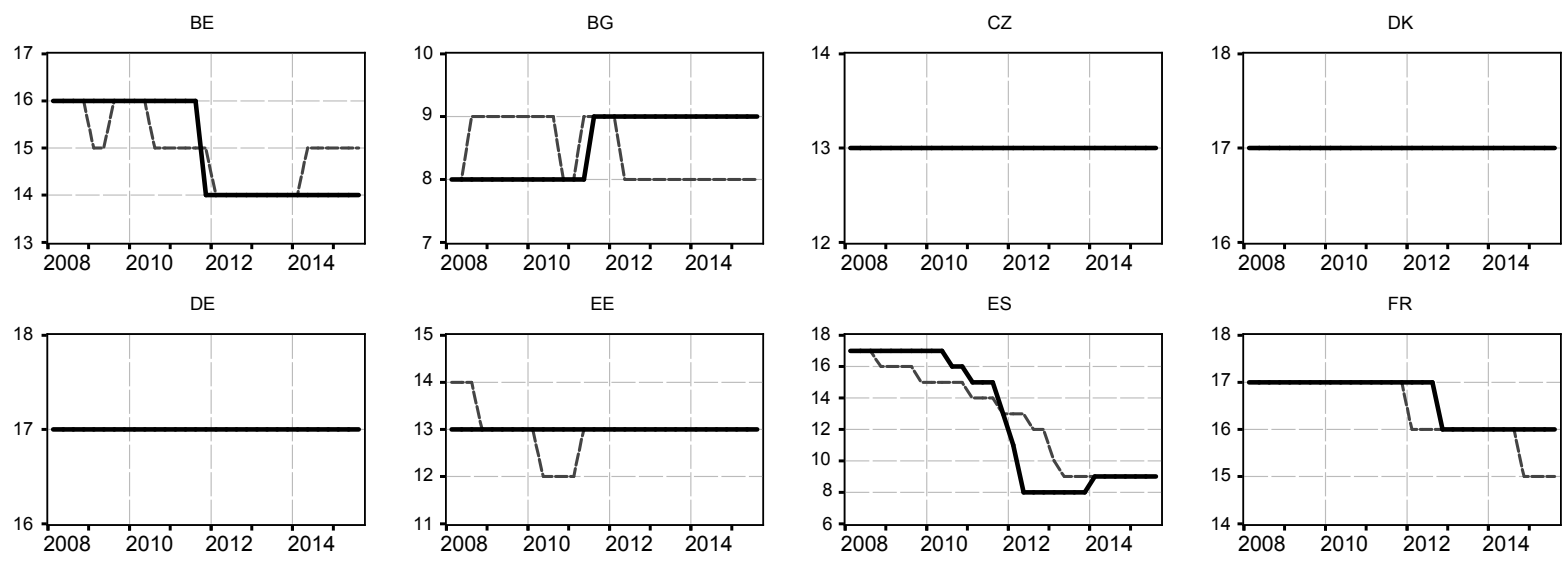

ES

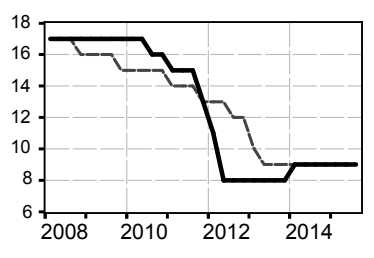

$\mathrm{FR}$
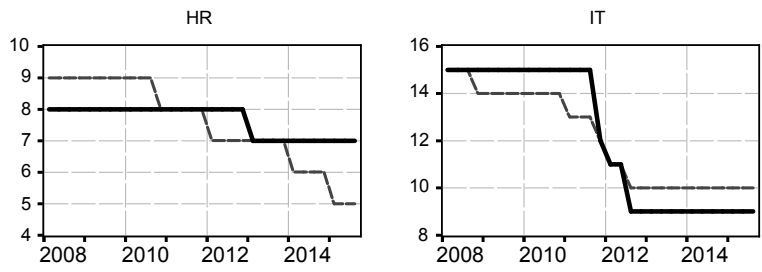

LV
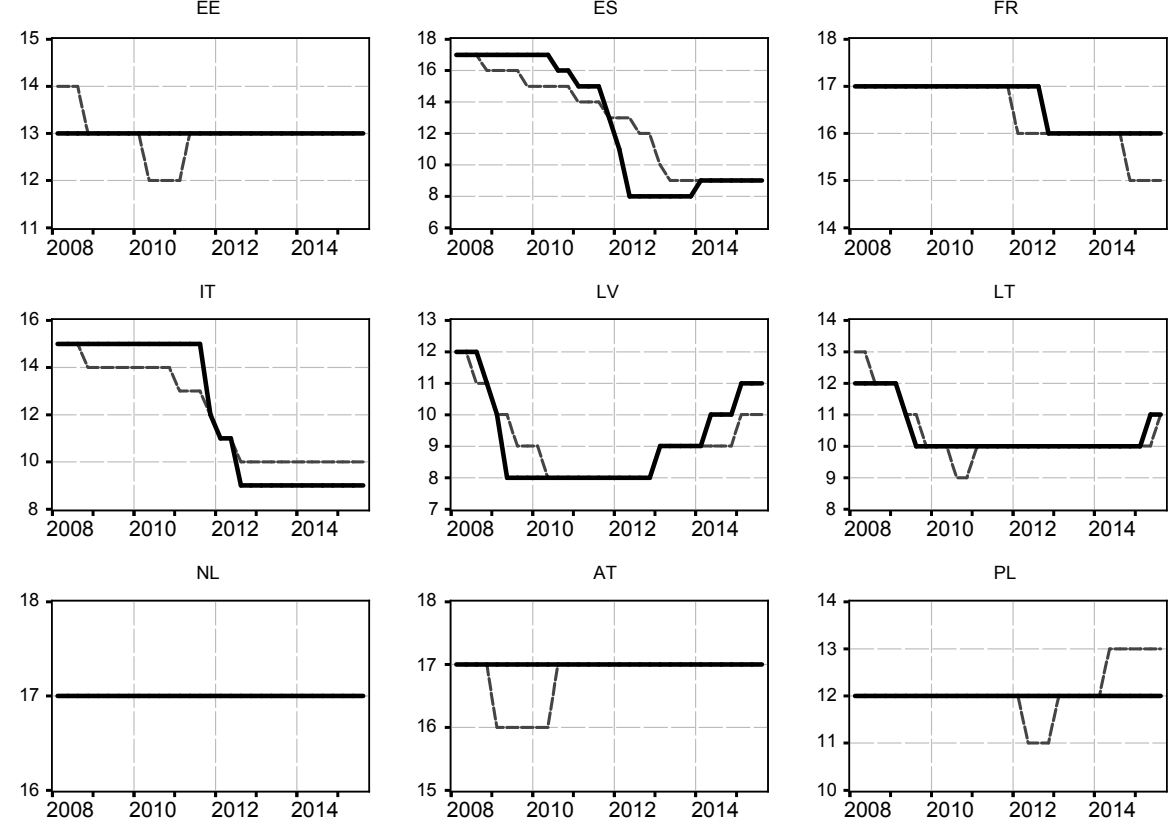

AT
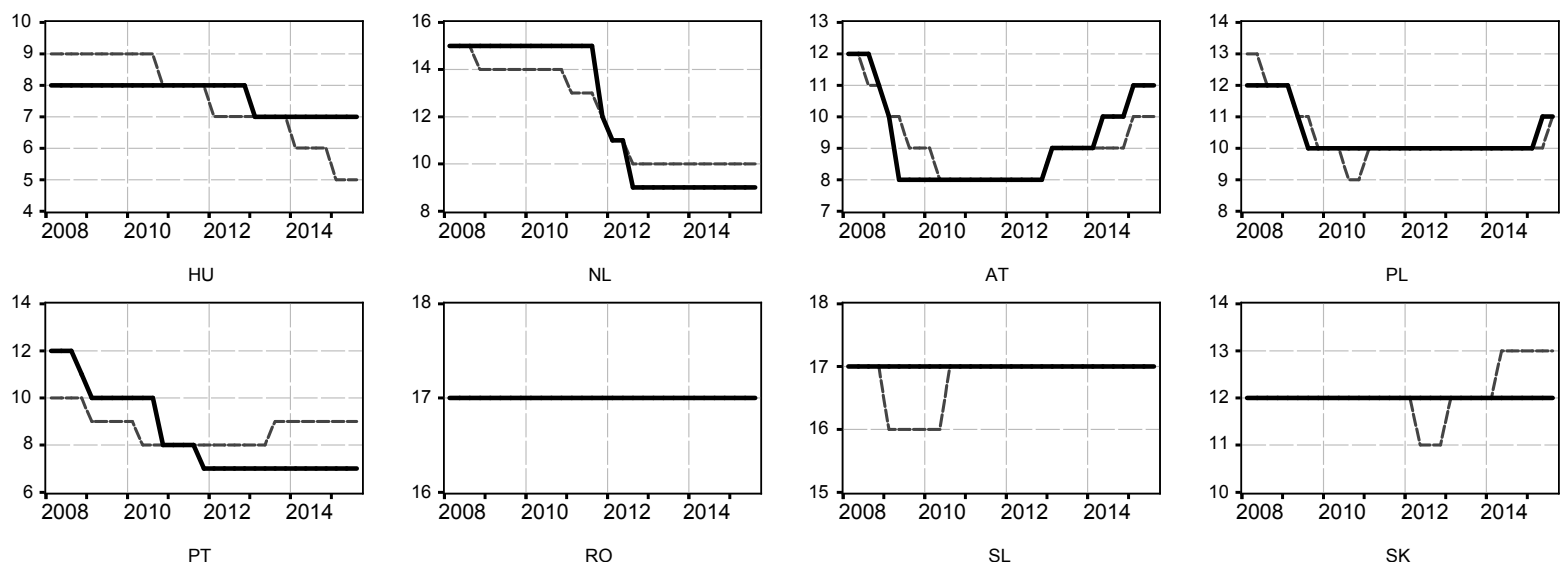

$\mathrm{RO}$
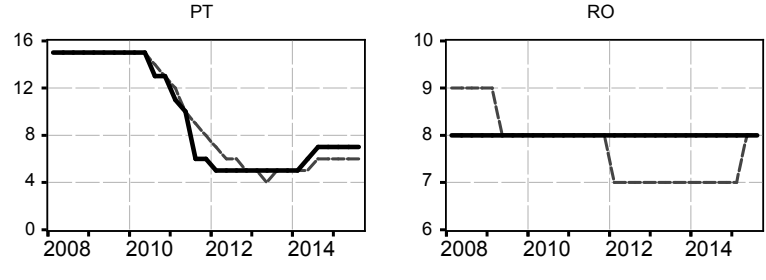

SL

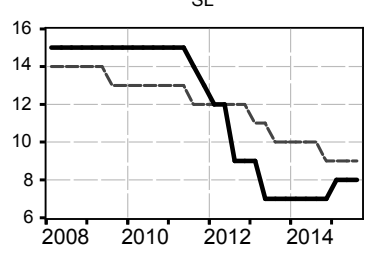

PL
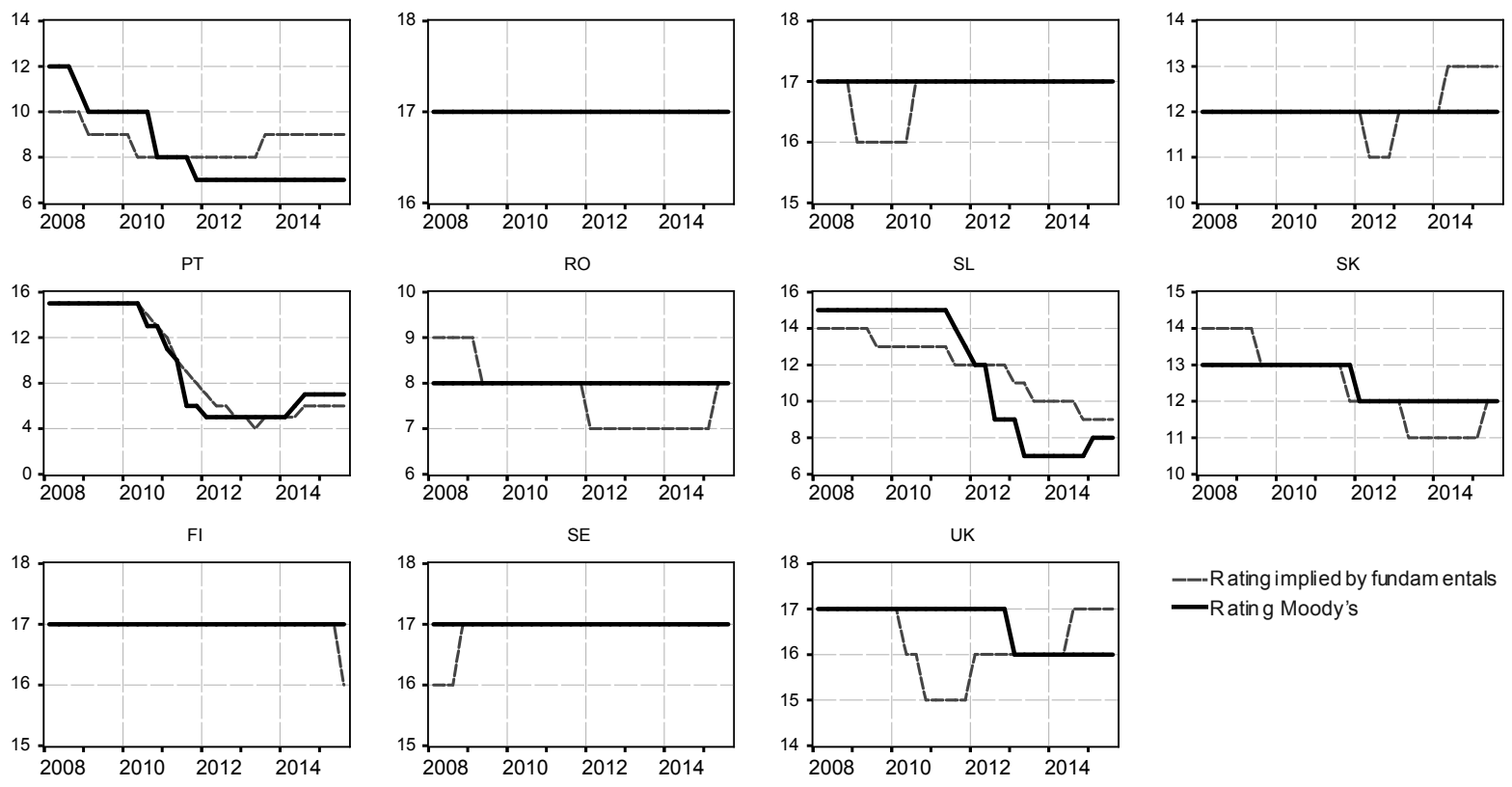

--R ating implied by fundam entals

-Rating Moody s 
Figure 3: Rating implied by fundamentals and observed rating for Fitch
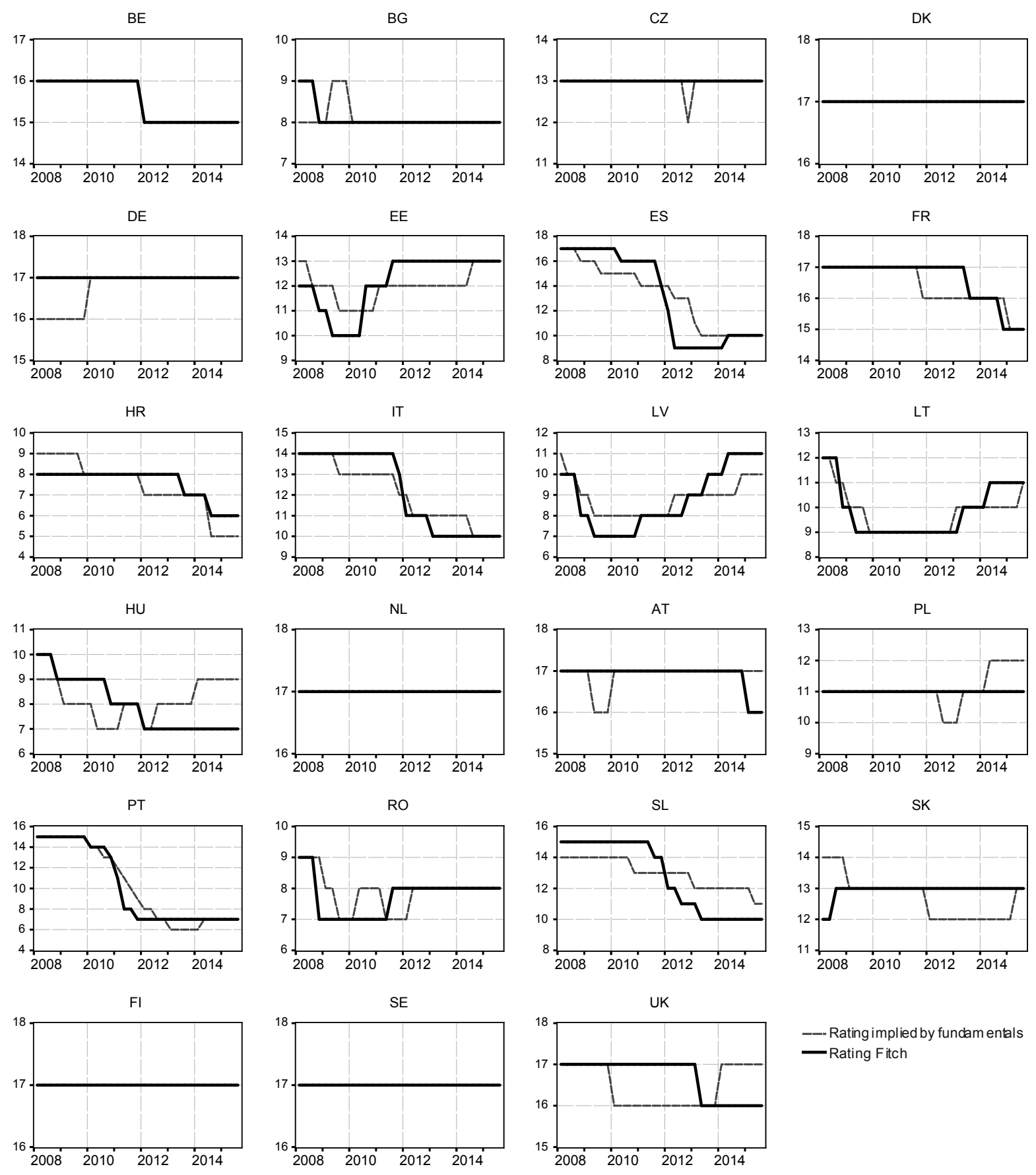

--- Rating implied by fundam entals - Rating Fitch 
Figure 4: Rating implied by fundamentals and observed average rating
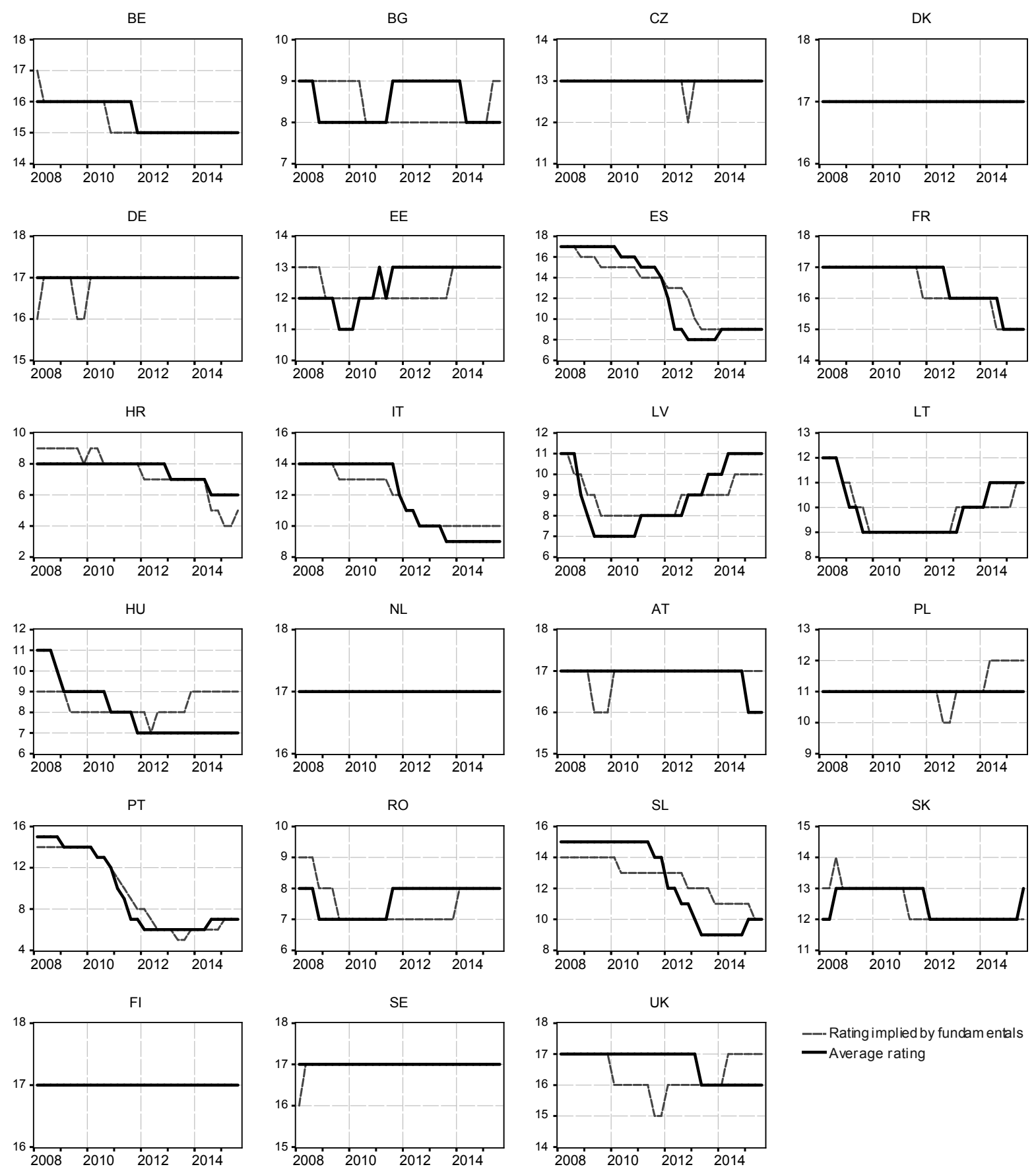

--- Rating implied by fundam entals

- Average rating 
Figure 5: Contribution of the rating overestimation indicator (S\&P) to the level of CDS spreads
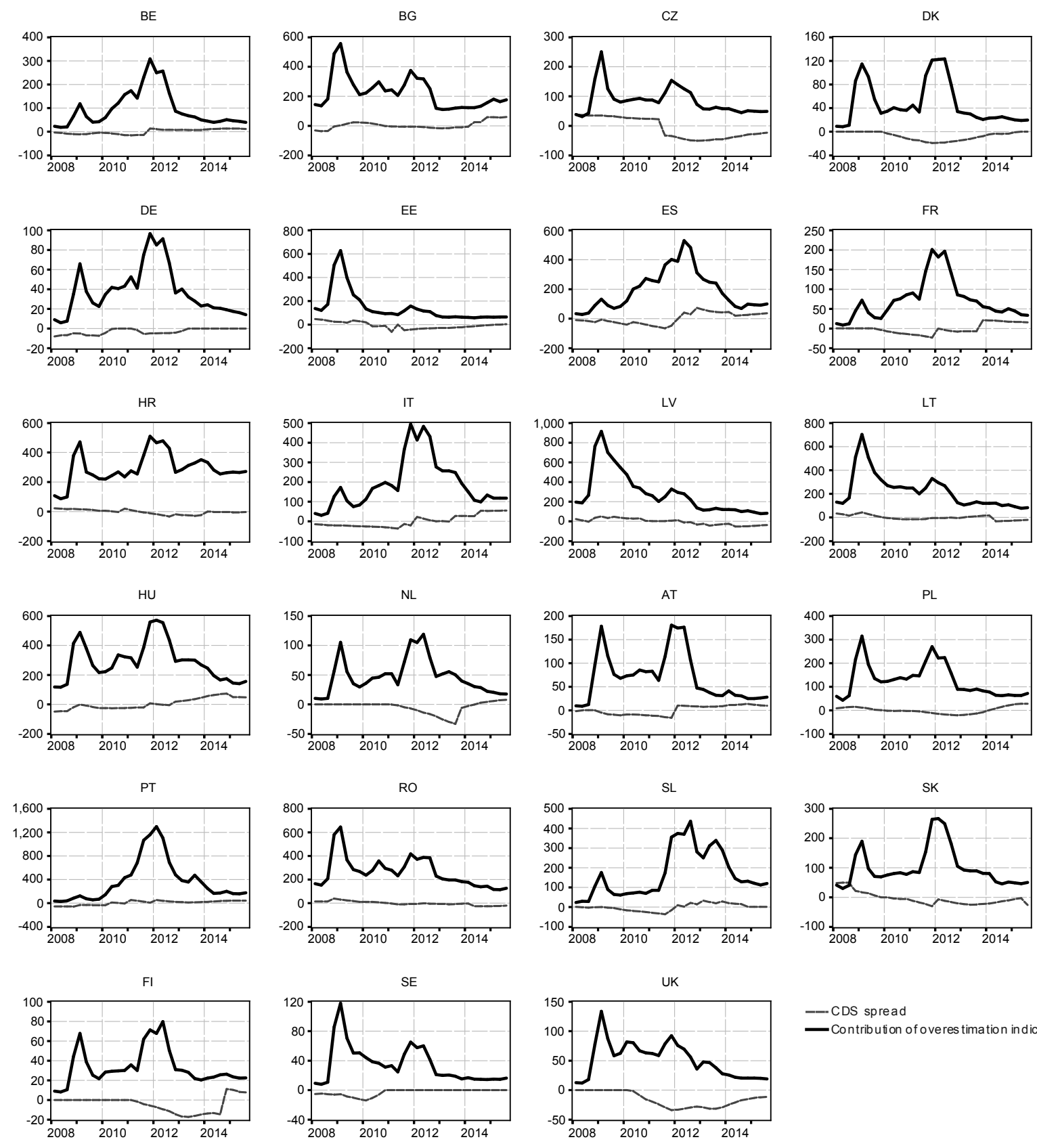

- CDS spread

- Con tribution of overes timation indicator 
Figure 6: Contribution of the rating overestimation indicator (Moody's) to the level of CDS spreads
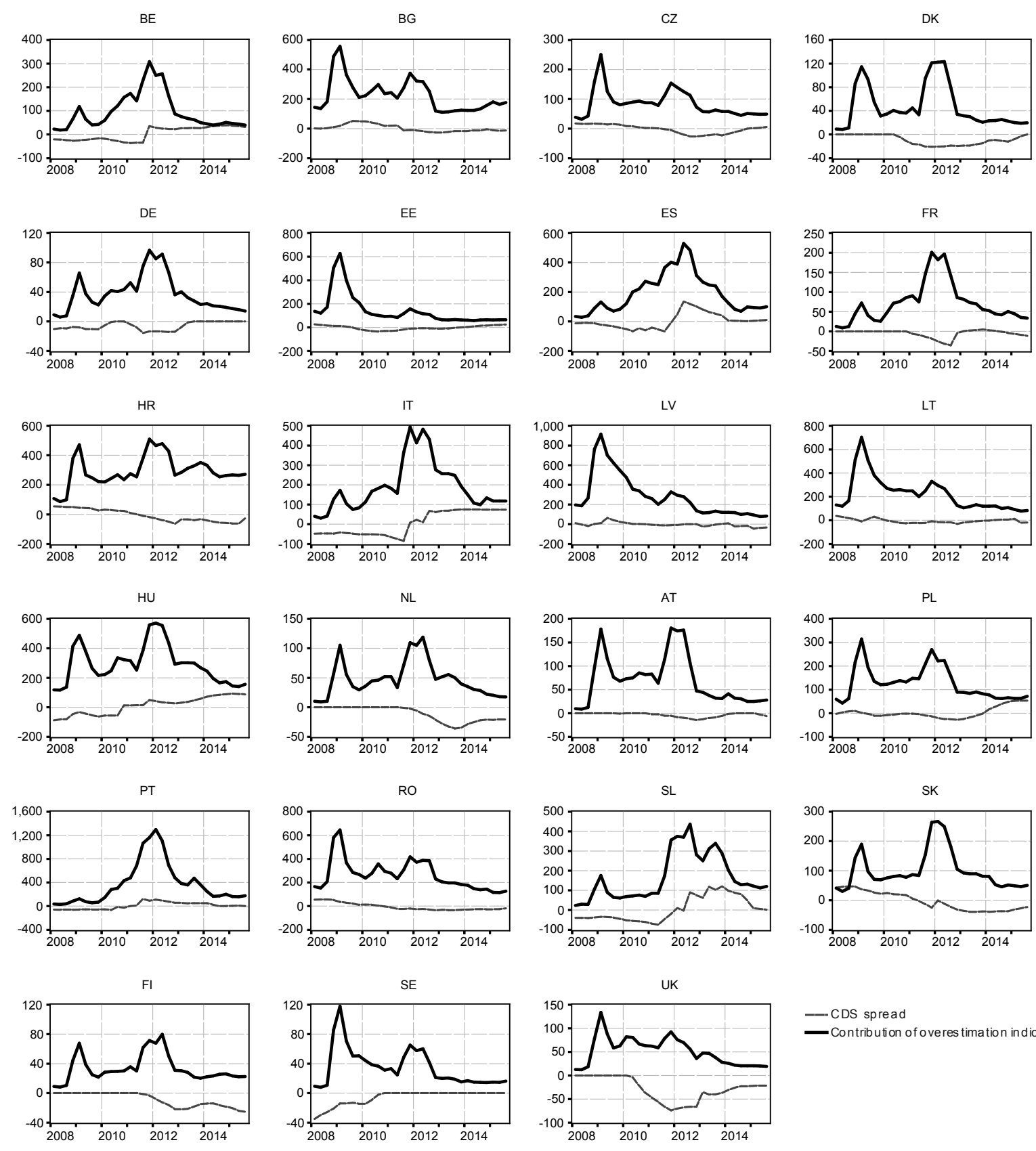

- CDS spread
Contribution o

- Contribution of overes timation in dicator 
Figure 7: Contribution of the rating overestimation indicator (Fitch) to the level of CDS spreads
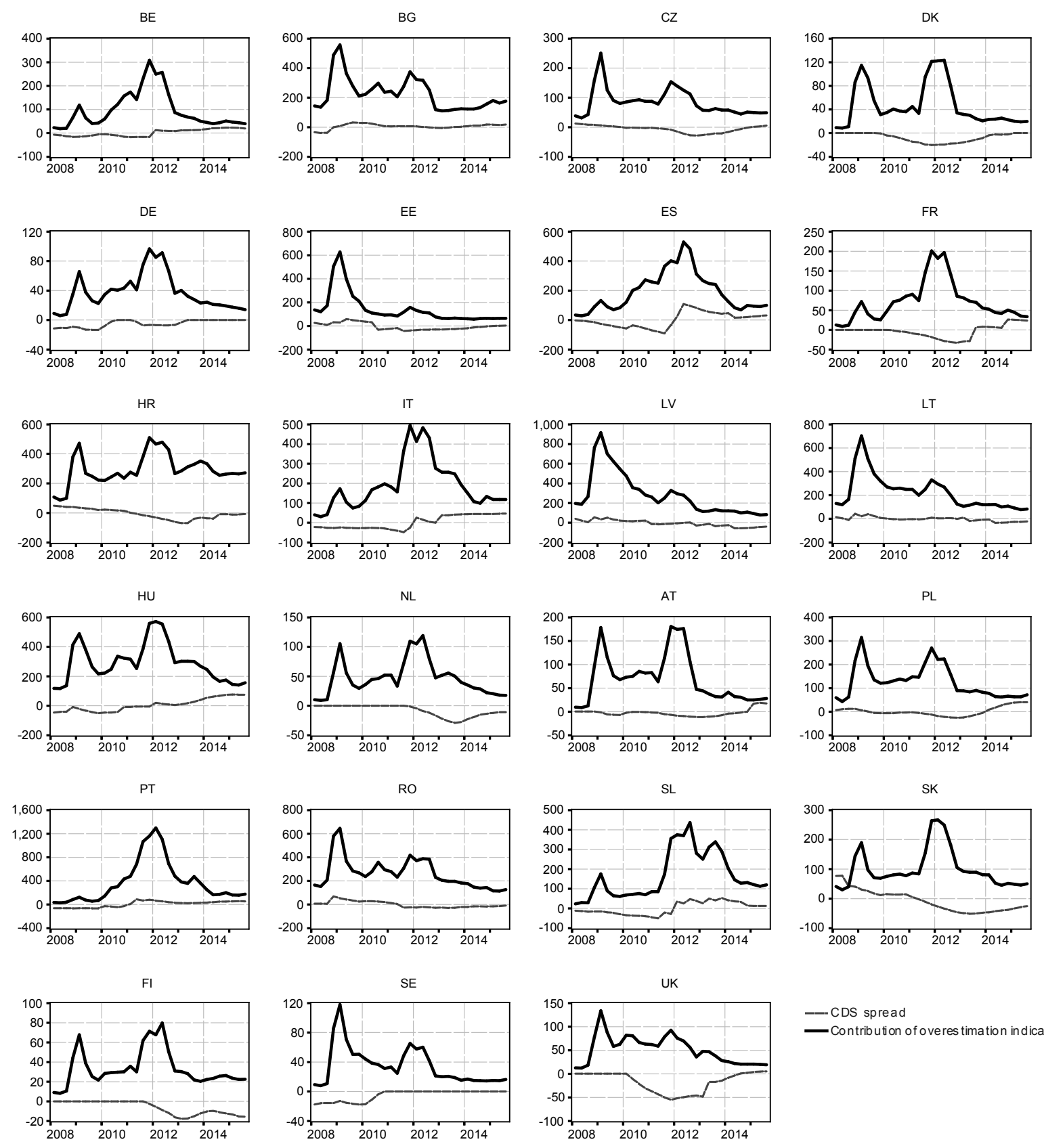

- CDS spread

- Contribution of overes timation indicator 
Figure 8: Contribution of the rating overestimation indicator (average rating) to the level of CDS spreads
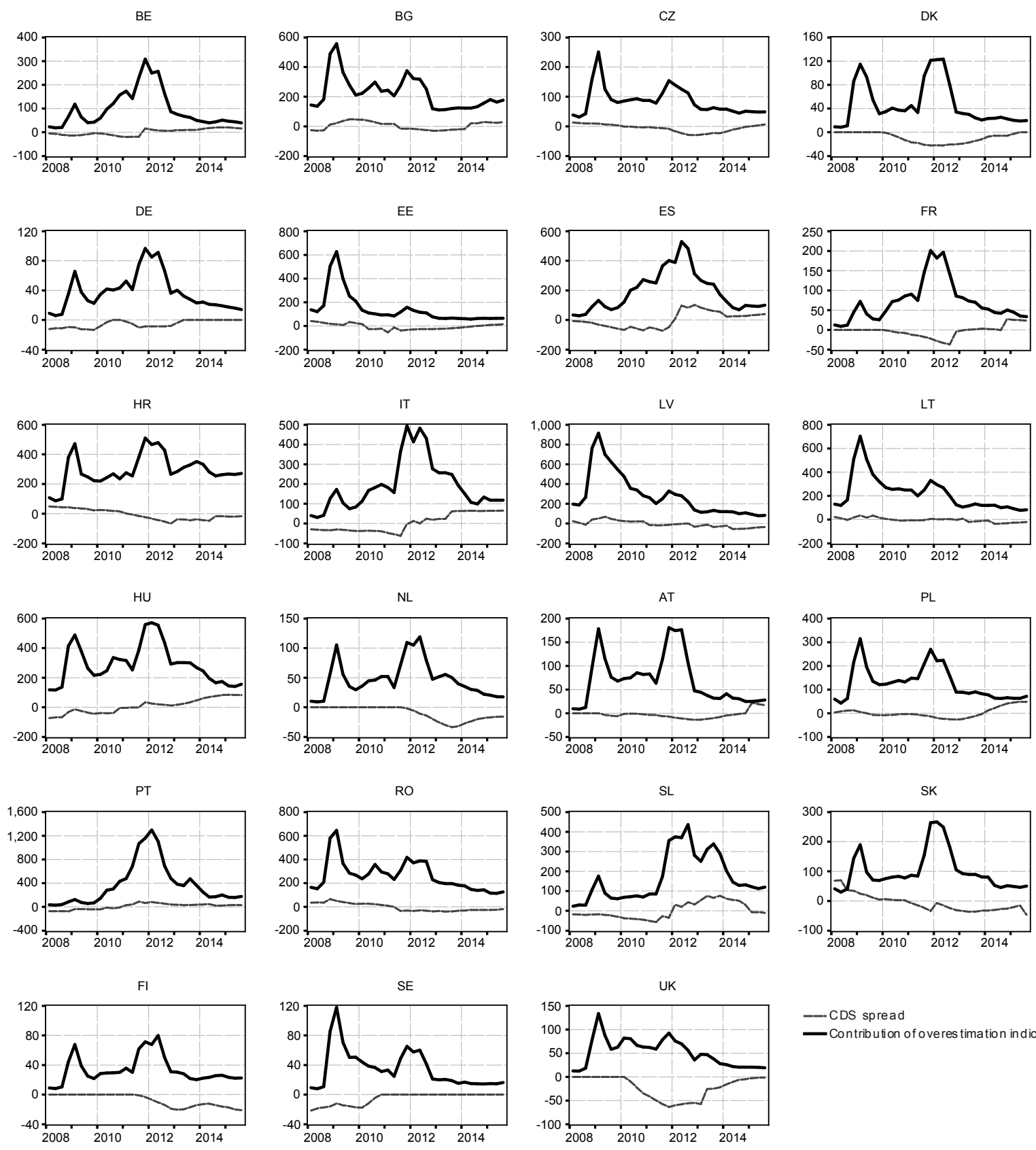

- CDS spread

- Contribution of overes timation indicator 
Figure 9: Market implied ratings
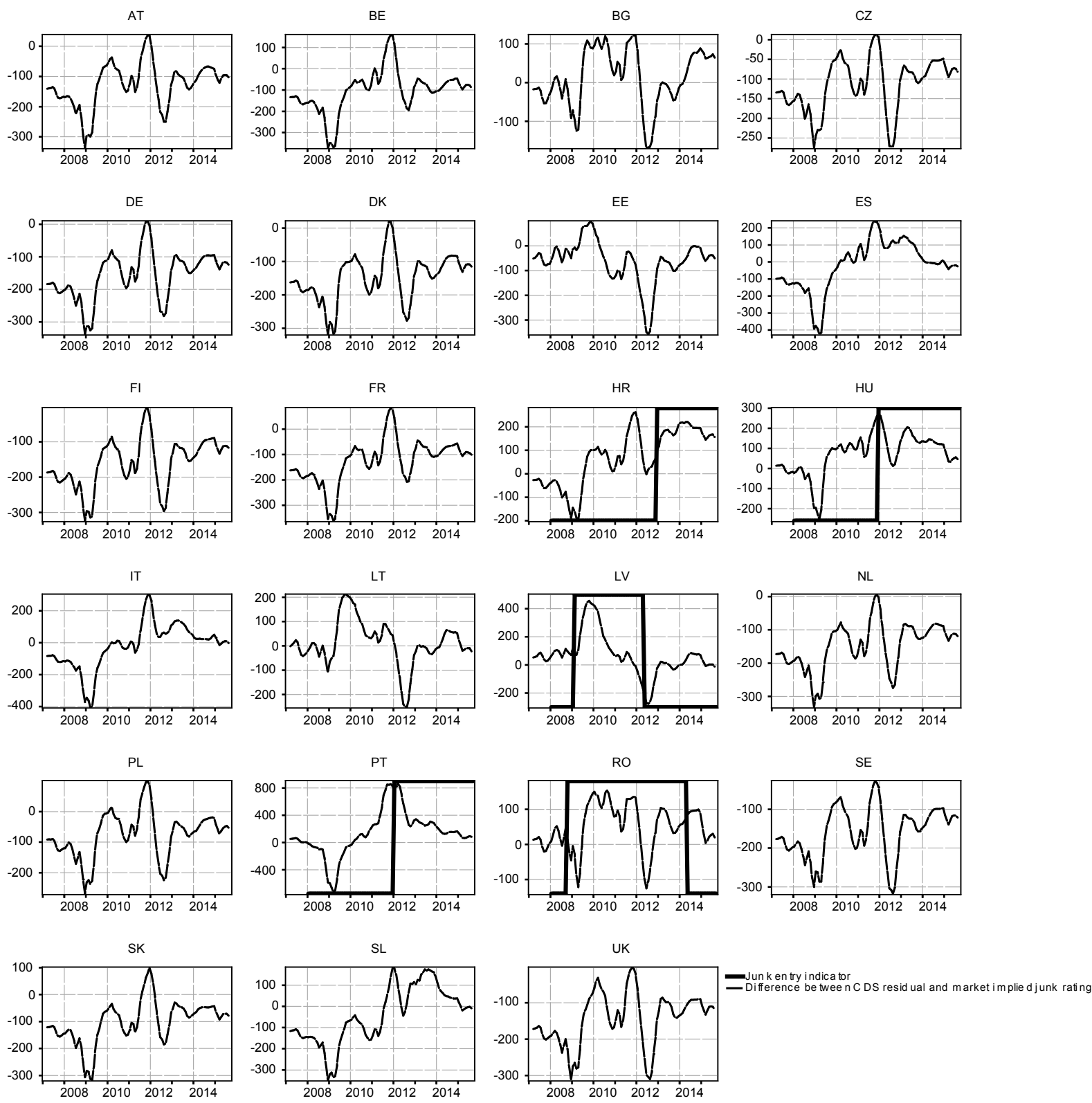

